\title{
Design and Fabrication of the First Commercial-Scale Liquid Phase Methanol (LPMEOH ${ }^{\mathrm{TM}}$ ) Reactor
}

\section{Topical Report}

October 1998
RECEIVED

DEC 281998

OSTI

Work Performed Under Contract No.: DE-FC22-92PC90543

\author{
For \\ U.S. Department of Energy \\ Office of Fossil Energy \\ Federal Energy Technology Center \\ P.O. Box 880 \\ Morgantown, West Virginia 26507-0880
}

By

Air Products and Chemicals Inc.

Allentown, Pennsylvania 


\section{Disclaimer}

This report was prepared as an account of work sponsored by an agency of the United States Government. Neither the United States Government nor any agency thereof, nor any of their employees, makes any warranty, express or implied, or assumes any legal liability or responsibility for the accuracy, completeness, or usefulness of any information, apparatus, product, or process disclosed, or represents that its use would not infringe privately owed rights. Reference herein to any specific commercial product, process, or service by trade name, trademark, manufacturer, or otherwise does not necessarily constitute or imply its endorsement, recommendation, or favoring by the United States Government or any agency thereof. The views and opinions of authors expressed herein do not necessarily state or reflect those of the United States Government or any agency thereof. 


\section{DISCLAIMER}

Portions of this document may be illegible in electronic image products. Images are produced from the best available original document. 


\begin{abstract}
$\underline{\text { Abstract }}$
The Liquid Phase Methanol (LPMEOH ${ }^{\mathrm{TM}}$ ) process uses a slurry bubble column reactor to convert synthesis gas (syngas), primarily a mixture of carbon monoxide and hydrogen, to methanol. Because of its superior heat management, the process can utilize directly the carbon monoxide $(\mathrm{CO})$-rich syngas characteristic of the gasification of coal, petroleum coke, residual oil, wastes, or other hydrocarbon feedstocks.

The LPMEOH ${ }^{\mathrm{TM}}$ Demonstration Project at Kingsport, Tennessee, is a $\$ 213.7$ million cooperative agreement between the U.S. Department of Energy (DOE) and Air Products Liquid Phase Conversion Company, L.P., a partnership between Air Products and Chemicals, Inc. and Eastman Chemical Company, to produce methanol from coal-derived syngas. Construction of the LPMEOH ${ }^{\mathrm{TM}}$ Process Demonstration Plant at Eastman's chemicals-from-coal complex in Kingsport was completed in January 1997. Following commissioning and shakedown activities, the first production of methanol from the facility occurred on April 2, 1997. Nameplate capacity of 260 short tons per day (TPD) was achieved on April 6, 1997, and production rates have exceeded 300 TPD of methanol at times.

This report describes the design, fabrication, and installation of the Kingsport LPMEOH ${ }^{\top M}$ reactor, which is the first commercial-scale LPMEOH ${ }^{\top \mathrm{M}}$ reactor ever built. The vessel is 7.5 feet in diameter and 70 feet tall with design conditions of $1000 \mathrm{psig}$ at $600^{\circ} \mathrm{F}$. These dimensions represent a significant scale-up from prior experience at the DOE-owned Alternative Fuels Development Unit in LaPorte, Texas, where 18-inch and 22-inch diameter reactors have been tested successfully over thousands of hours. The biggest obstacles discovered during the scaleup, however, were encountered during fabrication of the vessel. The lessons learned during this process must be considered in tailoring the design for future sites, where the reactor dimensions may grow by yet another factor of two.
\end{abstract}




\section{Table of Contents}

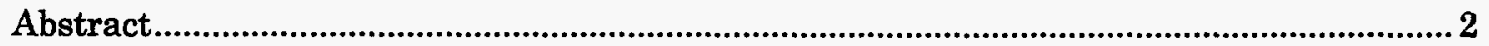

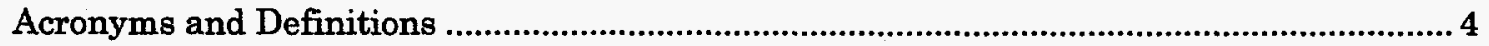

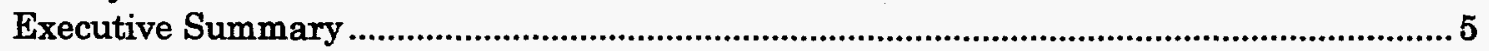

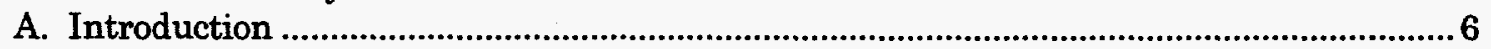

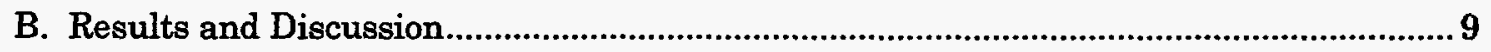

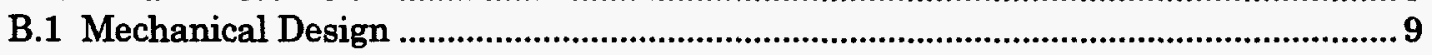

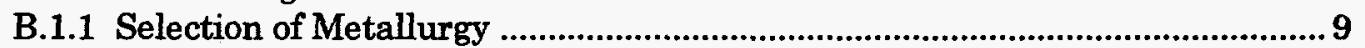

B.1.2 Selection of Design Conditions ................................................................ 10

B.1.3 Selection of Reactor Dimensions .......................................................... 11

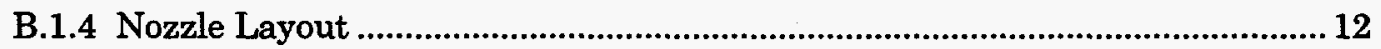

B.1.5 Nuclear Density Gauge and Traverse Issues ..................................................13

B.1.6 Calculation of Heat Transfer/Steam Circulation Performance ........................ 14

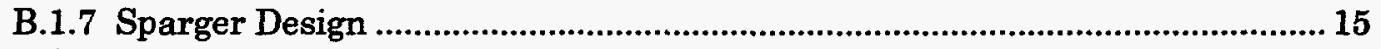

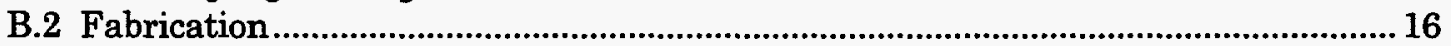

B.2.1 Vendor Selection and Shop Requirements.................................................16

B.2.2 Schedule - Proposed vs. Actual ........................................................................ 17

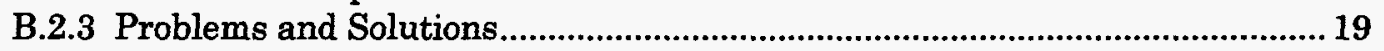

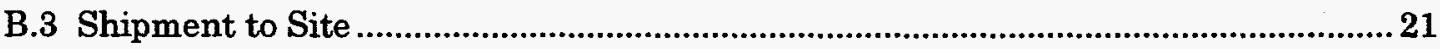

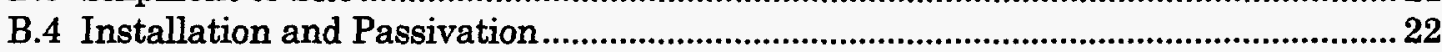

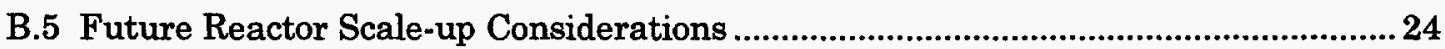

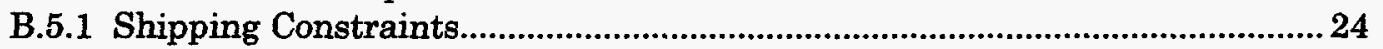

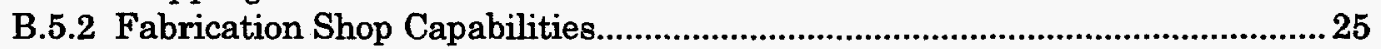

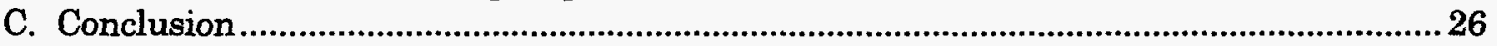

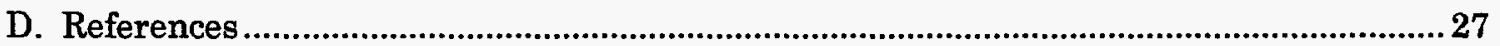

Appendix A - Process Flow Diagram and Reactor General Arrangement Drawing ............. 28

Appendix B - Photographs of Reactor Fabrication, Shipment, and Installation.....................29 


\section{Acronyms and Definitions}

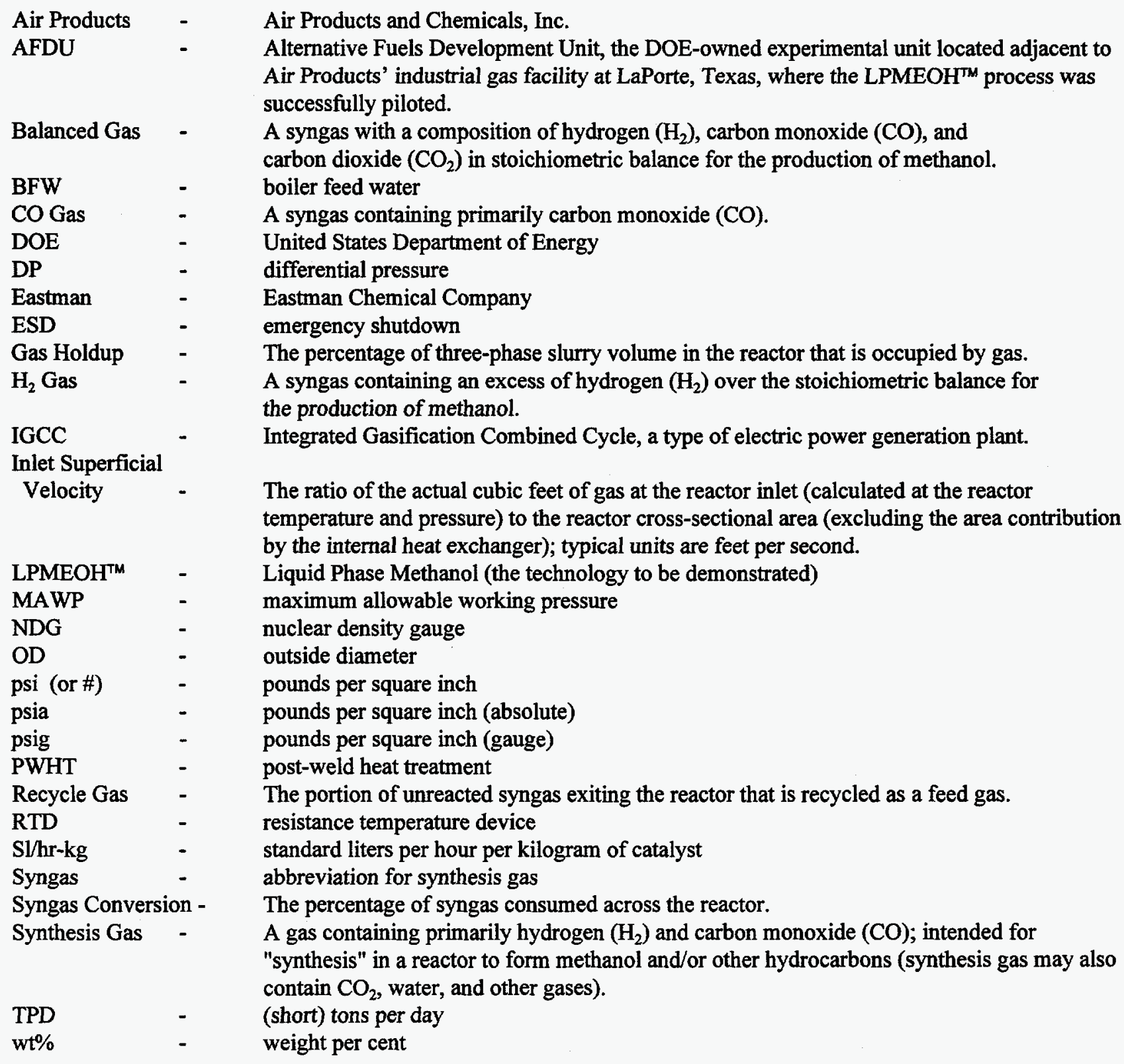




\section{Executive Summary}

The Liquid Phase Methanol (LPMEOH ${ }^{\mathrm{TM}}$ ) process uses a slurry bubble column reactor to convert synthesis gas (syngas), primarily a mixture of carbon monoxide and hydrogen, to methanol. Because of its superior heat management, the process can utilize directly the carbon monoxide (CO)-rich syngas characteristic of the gasification of coal, petroleum coke, residual oil, wastes, or other hydrocarbon feedstocks. When added to an integrated gasification combined cycle (IGCC) power plant, the LPMEOH ${ }^{\mathrm{TM}}$ process converts a portion of the CO-rich syngas produced by the gasifier to methanol, and the unconverted gas is used to fuel the gas turbine combined-cycle power plant. In addition, the $\mathrm{LPMEOH}^{\mathrm{TM}}$ process has the flexibility to operate in a daily load-following pattern, coproducing methanol during periods of low electricity demand, and idling during peak times. Coproduction of power and methanol via IGCC and the $\mathrm{LPMEOH}^{\mathrm{TM}}$ process provides opportunities for energy storage for electrical demand peak shaving, clean fuel for export, and/or chemical methanol sales.

The LPMEOH ${ }^{T M}$ Demonstration Project at Kingsport, Tennessee, is a $\$ 213.7$ million cooperative agreement between the U.S. Department of Energy (DOE) and Air Products Liquid Phase Conversion Company, L.P., a partnership between Air Products and Chemicals, Inc. and Eastman Chemical Company, to produce methanol from coal-derived syngas. Construction of the LPMEOH ${ }^{\mathrm{TM}}$ Process Demonstration Plant at Eastman's chemicals-from-coal complex in Kingsport was completed in January 1997. Following commissioning and shakedown activities, the first production of methanol from the facility occurred on April 2, 1997. Nameplate capacity of 260 short tons per day (TPD) was achieved on April 6, 1997, and production rates have exceeded 300 TPD of methanol at times.

This report describes the design, fabrication, and installation of the Kingsport LPMEOH ${ }^{\mathrm{MM}}$ reactor, which is the first commercial-scale LPMEOH ${ }^{\mathrm{TM}}$ reactor ever built. The vessel is 7.5 feet in diameter and 70 feet tall with design conditions of $1000 \mathrm{psig}$ at $600^{\circ} \mathrm{F}$. These dimensions represent a significant scale-up from prior experience at the DOE-owned Alternative Fuels Development Unit (AFDU) in LaPorte, Texas, where 18-inch and 22-inch diameter reactors have been tested successfully over thousands of hours. The biggest obstacles discovered during the scale-up, however, were encountered during fabrication of the vessel. The lessons learned during this process must be considered in tailoring the design for future sites, where the reactor dimensions may grow by yet another factor of two.

Although simpler in many respects than its conventional counterparts, the Kingsport LPMEOH ${ }^{\mathrm{TM}}$ reactor design was a complex, first-of-a-kind effort that presented many challenges for the vendor, including development of new methods for fabricating some of the components that went into the finished unit. The project schedule needed to incorporate a lead time of 20 to 22 weeks for non-standard material procurement, such as stainless steel-clad plate, 2205 duplex alloy tubing, and Inconel nozzle forgings. Even including this consideration, the reactor ultimately shipped from the vendor on June 14, 1996, eight months after the original 11-month schedule. 
The main problems were caused by fabrication errors, quality control issues, shop equipment problems, and sub-vendor delays.

There are a limited number of fabrication shops worldwide that can handle large, customfabricated, heavy-walled vessels. Any future scale-up of the reactor may further limit the list of potential fabricators to those who can roll heavier plate and have the crane capability to lift heavier vessels. Furthermore, the Kingsport $\mathrm{LPMEOH}^{\mathrm{TM}}$ reactor was large enough to require shipment by rail; larger and heavier reactors must be shipped by barge or ocean transport. Whether the reactor is shipped by rail or barge, the fabrication shop and job site must be accessible to these modes of transport. Air Products has worked with a few such fabrication shops in the past and has established procedures for ensuring that a quality product is shipped to the customer.

\section{A. Introduction}

The Liquid Phase Methanol (LPMEOH ${ }^{\mathrm{TM}}$ ) Demonstration Project at Kingsport, Tennessee, is a \$213.7 million cooperative agreement between the U.S. Department of Energy (DOE) and Air Products Liquid Phase Conversion Company, L.P., a partnership between Air Products and Chemicals, Inc. and Eastman Chemical Company, to produce methanol from coal-derived synthesis gas (syngas). Construction of the LPMEOH ${ }^{\mathrm{TM}}$ Process Demonstration Plant at Eastman's chemicals-from-coal complex in Kingsport was completed in January 1997. Following commissioning and shakedown activities, the first production of methanol from the facility occurred on April 2, 1997. Nameplate capacity of 260 short tons per day (TPD) was achieved on April 6, 1997, and production rates have exceeded 300 TPD of methanol at times.

Sponsored under the DOE's Clean Coal Technology Program, the LPMEOH ${ }^{\mathrm{TM}}$ Demonstration Project culminates an extensive cooperative development effort by Air Products and DOE in a program that began in 1981. By the late 1980s, the technology was proven in over 7,400 hours of test operation at a 10-TPD rate in the DOE-owned Alternative Fuels Development Unit (AFDU) in LaPorte, Texas. Developed to enhance electric power generation using integrated gasification combined cycle (IGCC) technology, the LPMEOH ${ }^{\mathrm{TM}}$ process exhibits several features essential for the economic coproduction of methanol and electricity in the IGCC scenario.

The slurry bubble column reactor differentiates the LPMEOH ${ }^{\mathrm{TM}}$ process from conventional technology. Conventional methanol reactors use fixed beds of catalyst pellets and operate in the gas phase. The LPMEOH ${ }^{\mathrm{TM}}$ reactor uses catalyst in powder form, slurried in an inert mineral oil. The mineral oil acts as a temperature moderator and heat removal medium, transferring the heat of reaction away from the catalyst surface to boiling water in an internal tubular heat exchanger. Since the heat transfer coefficients on both sides of the exchanger are relatively large, the heat exchanger occupies only a small fraction of the cross-sectional area of the reactor. As a result of this capability to remove heat and maintain a constant, highly uniform temperature throughout 
the entire length of the reactor, the slurry reactor can achieve much higher syngas conversion per pass than its gas-phase counterparts.

Furthermore, because of the LPMEOH ${ }^{\mathrm{TM}}$ reactor's unique temperature control capabilities, it can directly process syngas rich in carbon oxides (carbon monoxide and carbon dioxide). Gas-phase methanol technology would require that similar feedstocks undergo stoichiometry adjustment by the water-gas shift reaction, to increase the hydrogen content, and subsequent carbon dioxide $\left(\mathrm{CO}_{2}\right)$ removal. In a gas-phase reactor, temperature moderation is achieved by recycling large quantities of hydrogen $\left(\mathrm{H}_{2}\right)$-rich gas, utilizing the higher gas velocities around the catalyst particles and minimizing the conversion per pass. Typically, a gas-phase process is limited to carbon monoxide $(\mathrm{CO})$ concentrations of about $16 \%$ in the reactor feed, as a means of constraining the conversion per pass to avoid excess heating. In contrast, for the LPMEOH ${ }^{\mathrm{TM}}$ reactor, $\mathrm{CO}$ concentrations in excess of $50 \%$ have been tested routinely in the laboratory and at the AFDU in LaPorte, without any adverse effect on catalyst activity. As a result, the LPMEOH $^{\mathrm{TM}}$ reactor can achieve approximately twice the conversion per pass of the gas-phase process, yielding lower recycle gas compression requirements and capital savings.

A second distinctive feature of the $\mathrm{LPMEOH}{ }^{\mathrm{TM}}$ reactor is its robust character. The slurry reactor is suitable for rapid ramping, idling, and even extreme stop/start actions. The thermal moderation provided by the liquid inventory in the reactor acts to buffer sharp transient operations that would not normally be tolerable in a gas-phase methanol synthesis reactor. This characteristic is especially advantageous in the environment of electricity demand load-following in IGCC facilities.

A third differentiating feature of the LPMEOH ${ }^{\mathrm{TM}}$ process is that a high quality methanol product is produced directly from syngas rich in carbon oxides. Gas-phase methanol synthesis, which must rely on $\mathrm{H}_{2}$-rich syngas, yields a crude methanol product with $4 \%$ to $20 \%$ water by weight. The product from the LPMEOH ${ }^{\mathrm{TM}}$ process, using CO-rich syngas, typically contains only $1 \%$ water by weight. As a result, raw methanol coproduced in an IGCC facility would be suitable for many applications at a substantial savings in purification costs. The steam generated in the LPMEOH $^{\mathrm{TM}}$ reactor is suitable for purification of the methanol product to a higher quality or for use in the IGCC power generation cycle.

Another unique feature of the LPMEOH ${ }^{\mathrm{TM}}$ process is the ability to withdraw spent catalyst slurry and add fresh catalyst on-line periodically. This facilitates uninterrupted operation and also allows perpetuation of high productivity in the reactor. Furthermore, choice of catalyst replacement rate permits optimization of reactor productivity versus catalyst replacement cost.

At the Eastman complex in Kingsport, Tennessee, the technology is integrated with coal gasifiers that have operated commercially since 1983 . Texaco gasification converts about 1,000 tons-perday of high-sulfur, Eastern bituminous coal to syngas for the manufacture of methanol, acetic anhydride, and associated products. The LPMEOH ${ }^{\mathrm{TM}}$ Demonstration Plant occupies an area of 0.6 acre within the 4,000-acre Eastman complex. 
Appendix A includes a simplified process flow diagram. Syngas enters the bottom of the slurry reactor, which contains solid particles of catalyst suspended in liquid mineral oil. The syngas dissolves through the mineral oil, contacts the catalyst surface, and reacts to form methanol. The highly exothermic heat of reaction is absorbed by the slurry and removed from the reactor by steam coils. The product methanol vapor exits the reactor with unreacted syngas, is condensed to a liquid, and sent to distillation columns for removal of higher alcohols, water, and other impurities. Most of the unreacted syngas is returned to the reactor by the syngas recycle compressor, improving overall cycle efficiency.

A carefully developed test plan will allow operations to simulate electricity demand loadfollowing in coal-based IGCC facilities. The operations will also demonstrate the enhanced stability and heat dissipation of the conversion process, its reliable on/off operation, and its ability to produce methanol as a clean liquid fuel without additional upgrading. An off-site, product-use test program will demonstrate the suitability of the methanol product as an environmentally-advantaged alternative fuel in stationary and transportation applications.

This report describes the design, fabrication, and installation of the Kingsport LPMEOH ${ }^{\mathrm{TM}}$ reactor, which is the first commercial-scale $\mathrm{LPMEOH}^{\mathrm{TM}}$ reactor ever built. The vessel is 7.5 feet in diameter and 70 feet tall with design conditions of $1000 \mathrm{psig}$ at $600^{\circ} \mathrm{F}$. These dimensions represent a significant scale-up from prior experience at the AFDU, where 18-inch and 22-inch diameter reactors have been tested successfully over thousands of hours. The biggest obstacles discovered during the scale-up, however, were encountered during fabrication of the vessel. The lessons learned during this process must be considered in tailoring the design for future sites, where the reactor dimensions may grow by yet another factor of two. 


\section{B. Results and Discussion}

\section{B.1 Mechanical Design}

The $\mathrm{LPMEOH}^{\mathrm{TM}}$ reactor design, fabrication, and installation was a critical path item for the Kingsport LPMEOH ${ }^{\mathrm{TM}}$ Demonstration Project. The reactor was the second major process equipment specification developed after project kickoff, following only the recycle compressor specification and selection. Then, the Air Products pressure vessel design team developed a detailed mechanical specification and layout drawing for the reactor vessel and internals, including the overall nozzle orientation, vessel internal heat exchanger piping and supports, and gas inlet sparger details. This package gave the bidders a realistic expectation of the final design, while giving plant layout designers a head start on their task prior to final drawing approval.

\section{B.1.1 SELECTION OF METALLURGY}

The metal surfaces in contact with syngas inside the $\mathrm{LPMEOH}^{\mathrm{TM}}$ reactor must be made of a stainless steel alloy to reduce the potential for iron and nickel carbonyl $\left(\mathrm{Fe}(\mathrm{CO})_{5}\right.$ and $\left.\mathrm{Ni}(\mathrm{CO})_{4}\right)$ formation. ${ }^{1,2}$ Carbonyls, which act as poisons when deposited on the catalyst, are formed when carbon monoxide at high temperature and high partial pressure contacts free iron or nickel on metal surfaces. Stainless steels limit carbonyl formation because the chromium in the alloy will form chromium oxide $\left(\mathrm{Cr}_{2} \mathrm{O}_{3}\right)$ on the metal surface and thereby provide a resistant, passive layer that prevents further reaction. Below a certain critical chromium content, the chromium oxide is unable to form a continuous passive film to protect the surface. This phenomenon has been observed with iron, nickel, and cobalt alloys, and in general, the reactivity resistance of stainless steels increases as the chromium content is increased.

At the LaPorte AFDU, Air Products has had success fabricating the reactor shell from Type 304 stainless steel (19 wt\% chromium). However, at commercial scale, fabricating the reactor from solid stainless steel was not economical because of the wall thickness required. Significant cost savings could be achieved by using stainless-clad carbon steel for the shell, heads, and nozzles. For Kingsport, 3/16-inch 304L-grade stainless steel was specified for the cladding; the carbon steel backing plate has a thickness of $23 / 4$ inches.

Material selection for the reactor's internal heat exchanger also required a step-out from previous experience at the LaPorte AFDU. The heat exchanger is welded to the reactor shell at the riser outlet nozzles at the top, and at the downcomer inlet nozzles at the bottom. The metallurgy must be able to handle thermal stresses associated with expansion and contraction during heating and cooling at startup and shutdown. The material selected for the internal heat exchanger bundle was 2205 duplex stainless alloy.

The 2205 duplex alloy has three main advantages over 316 stainless steel: it has greater strength, allowing the use of less-expensive, thinner-walled material; it has higher thermal conductivity; and, it is more resistant to chloride and caustic cracking. The 2205 duplex alloy is an extremely 
strong, lightweight material which simplified the structural design by eliminating the need for additional flexibility loops, support bars, or ledges. The chloride resistance of the alloy is important because chloride levels in boiler feed water (BFW) often cause problems with standard 300-series stainless steels. However, the aforementioned carbonyl concerns on the slurry side required stainless-type metallurgy. Fortunately, 2205 duplex alloy is considered more corrosionresistant and less likely to form carbonyls than either Type 316 or 304 stainless steel because the chromium content is higher ( $22 \%$ vs. $17 \%$ for 316 and $19 \%$ for 304$)$. Test data support these conclusions.

One shortcoming of the 2205 duplex alloy is that it is not rated by the ASME code at temperatures above $600{ }^{\circ} \mathrm{F}$ for any pressure. Although the material will not fail catastrophically above these temperatures, it can experience reduced life cycles, possibly leading to failure after repeated excursions. To prevent this, three high temperature emergency shutdowns (ESD's) on the slurry side of the heat exchanger protect the reactor from ever approaching $600{ }^{\circ} \mathrm{F}$. On the steam side, high temperature shutoffs just outside the riser and downcomer nozzle connections protect against overheating by the $750 \circ$ F startup steam. Since the startup steam should only be introduced when the risers, downcomers, and steam drum are full of BFW, those high temperature switches should never be exposed to temperatures above $600^{\circ} \mathrm{F}$ if operating procedures are followed properly.

The nozzles connecting the 2205 alloy tubes to the stainless-clad carbon steel plate are made of Inconel 600 . This choice of material limits the stresses associated with different rates of thermal growth by the reactor's carbon steel outer shell, its 304L-grade stainless steel cladding, and the 2205 alloy tubes. Inconel nozzles also allow the fabricator to do post-weld heat treatment (PWHT) of the vessel before final insertion of the tube bundle to protect the bundle from the high $\left(1100^{\circ} \mathrm{F}\right) \mathrm{PWHT}$ temperatures.

Special flanges were fabricated to match some of the reactor nozzles (carbon steel with stainless steel weld overlay) to piping of different metallurgy. For example, the differential pressure (DP) taps (nozzles R1-R9) are 1 1/2-inch carbon steel "600\#" nozzles which mate with stainless steel "1500\#" flange piping. For simplicity, future reactors should be constructed with flanges that match the ratings of the connecting stainless steel piping, rather than the typically lower-rated flanges allowed for carbon steel nozzles. In this case, the flanges would be either "900\#" or "1500\#", instead of the "600\#" allowed for the carbon steel flanges.

\section{B.1.2 SELECTION OF DESIGN CONDITIONS}

The design pressure of the $\mathrm{LPMEOH}{ }^{\mathrm{TM}}$ reactor was selected as $1000 \mathrm{psig}$ at $600^{\circ} \mathrm{F}$. As mentioned previously, the 2205 alloy metallurgy used for the internal tube bundle constrains the design temperature limit from being any higher. Typical operating temperature for the reactor is $482^{\circ} \mathrm{F}$, with operations possible up to $510^{\circ} \mathrm{F}$, especially if liquid-phase dimethyl ether technology were to be pursued. From experience at the LaPorte AFDU, the controllable range on reactor temperature has generally been within $+/-3^{\circ} \mathrm{F}$, with upsets rarely exceeding $+/-10^{\circ} \mathrm{F}$ 
from setpoint. Furthermore, the methanol synthesis reaction is self-limited by equilibrium and cannot run away. Thus, the $600^{\circ} \mathrm{F}$ design limit provides an appropriate margin for operating excursions.

Typical syngas supply pressure from Eastman was expected to result in an operating pressure of $750 \mathrm{psia}$ at the top of the reactor. However, since higher pressure favors the methanol reaction rate, the LPMEOH ${ }^{\mathrm{M}}$ plant would benefit from any efforts by Eastman to de-bottleneck their syngas generation loop and raise the supply pressure. Thus, it was desirable to build in flexibility to operate at higher pressures. In addition, for "900\#" 304L-grade stainless steel flanges, the true design limit is $1000 \mathrm{psig}$ at $600^{\circ} \mathrm{F}$. Therefore, $1000 \mathrm{psig}$ at $600^{\circ} \mathrm{F}$ was selected as the reactor circuit's maximum allowable working pressure (MAWP).

\section{B.1.3 SELECTION OF REACTOR DIMENSIONS}

The Kingsport LPMEOH ${ }^{\mathrm{TM}}$ reactor was sized after a lengthy series of process optimization studies, which considered varying amounts of recycle and three different feed streams to determine their effects on reactor feed composition, production, and syngas utilization. Fixing the reactor diameter at 7.5 feet results in an inlet superficial velocity of $0.63 \mathrm{ft} / \mathrm{sec}$ at design feed rates. The reactor height was set by a space velocity of 4000 [S1/hr-kg catalyst oxide], to maximize syngas conversion, and adequate freeboard to limit slurry entrainment.

Since this facility is a demonstration plant with four years of test operations, both higher superficial velocities and higher catalyst loadings will be tested to maximize reactor volumetric efficiency. For future commercial opportunities, the designs will push to higher superficial velocities to narrow the reactor diameter and reduce cost. In addition, since complete conversion of syngas is not a primary goal in an IGCC facility, as it is in a coal-to-chemicals facility like Kingsport, future reactors would likely be designed for higher space velocities. The design velocity was selected because it was in the upper range of the successful experience envelope for extended operations during the proof-of-concept tests at the LaPorte AFDU (1988/89). Although more recent tests at the AFDU have exceeded this limit, these tests have lasted for shorter, 24hour periods. ${ }^{3}$ Operation at maximum rates at Kingsport will push the velocity significantly past the design value. The main reason for selecting $0.63 \mathrm{ft} / \mathrm{sec}$, however, was to demonstrate a reasonable scale-up of diameter from the reactors at the LaPorte AFDU ( 7.5 feet vs. 18 inches and 22 inches). A $1 \mathrm{ft} / \mathrm{sec}$ design, for example, would have required only a 6-foot diameter reactor.

To maximize reactor volumetric productivity, one of the goals of the demonstration period is to determine the maximum slurry level and minimum freeboard section. Two main factors can limit slurry level: significant entrainment of slurry out of the reactor; or, improper temperature control, if operating in the region above the heat exchanger. Estimation of entrainment was based on operating data from the LaPorte AFDU, as well as theoretical correlations. Both methods predict low levels of entrainment, but the LaPorte data may be skewed by the large ratio of wall surface area to cross-sectional area. One of the program goals aims to gain further 
understanding of entrainment as a function of freeboard height and superficial gas velocity. Any non-isothermal temperature effects of operating at slurry levels above the tube bundle should be recorded by the 35 thermocouples located every four feet axially, and at two different angles and three depths radially. These thermocouples can also serve as an independent level measurement because temperature generally drops in the freeboard.

\section{B.1.4 NOZZLE LAYOUT}

The general outline drawing for the Kingsport reactor, included in Appendix A, helps to describe the nozzle layout. The syngas feed and effluent nozzles ("A" and " $H$ ", respectively) were placed directly in the center of the 2:1 elliptical bottom and top heads. For the feed nozzle, this choice was especially important in designing a symmetrical sparger system. An off-center feed nozzle or pair of nozzles, could have ensured complete drainage of the slurry during maintenance outages (by positioning the slurry transfer nozzle in the center), but it also would have been more costly, crowded, and complicated. The lower 24-inch access port, "N2", was placed on the bottom head to allow for inspection, removal, and re-installation of the gas sparger. Once removed, access is then available to the bottom of the tube bundle. A vented plug, with a stainless steel-clad surface inside the reactor, was incorporated to prevent accumulation of catalyst in the access port, which could become a significant nuisance when the access port was opened.

Two 2-inch slurry transfer nozzles were provided: "B" for continuous return of entrained slurry and/or fresh makeup oil; " $W$ " for the batch operations of slurry addition and withdrawal and maintenance drains. The separate nozzles also allow more flexibility in the event either line plugs with slurry. A spare 4-inch nozzle "P" was added to the bottom head to allow for the potential future use of radioactive tracer injections. This nozzle could allow a fit-up of some sort of sparger arrangement for test injections in different radial positions within the vessel.

Nine $1 \frac{1}{2}$-inch nozzles ("R1"- "R9") were placed in the top and bottom heads and axially along the shell to facilitate DP measurement across the entire length of the reactor, across 10-foot sections of slurry, and across the reactor sparger. This coverage should permit accurate calculation of gas holdup in the slurry. As a precaution, oil back-flush connections were provided to each of these DP taps, although experience in a one-month run at the LaPorte AFDU did not require the use of flushes. Plates were welded onto the external shell of the reactor to support the piping for the DP cells while still allowing flexibility for thermal growth of the reactor.

Temperature measurements provide an indication of the reactor mixing properties, possible steam circuit maldistribution problems, location of the slurry level, and most importantly, the isothermal properties of a large-scale slurry bubble column. The " $\mathrm{J}$ " nozzles (4 feet apart axially) provide single resistance temperature device (RTD) readings at staggered insertion lengths of 12,24 , and 36 inches $(26,38$, and 50 -inch $304 \mathrm{~L}$ barstock, respectively, minus the 14 inch nozzle length). Nozzle " $\mathrm{J} 4$ " is located 5 inches lower than intended because of a misplaced 
weld seam. The "K" nozzles ( 8 feet apart axially and $218^{\circ}$ from the "J" nozzles) utilize RTD rakes, which incorporate multiple measurements on a single "probe", to measure the temperature at three radial positions in the same plane $(12,24$, and 36 inches from the wall). All " $\mathrm{J}$ " and " $\mathrm{K}$ " nozzles were standardized at $1 \frac{1}{2}$-inch carbon steel (SA350-LF2) clad with 304L stainless steel. The " $\mathrm{K}$ " nozzle bore was sized to allow the insertion of a 3/4-inch nominal diameter (1.050 inch OD) Schedule 80S rake. "J" and " $K$ " nozzle locations were checked at the fabricator's shop to allow clear insertion of $50^{+}$-inch long, $3 / 4$-inch nominal diameter dummy thermocouples. However, once the reactor stood vertical in the field, some of the " $\mathrm{K}$ " nozzles were obstructed, requiring redistribution of some RTD rakes to the "J" nozzles.

Since the rakes are long and unsupported, an analysis was performed to investigate the stress that could result at the cantilevered end during a slurry slump test. The worst-case scenario envisioned that the slurry bed would collapse completely in five seconds, and the rake would be exposed to a slurry impact velocity of $10 \mathrm{ft} / \mathrm{sec}$. The resulting stress was less than $10,000 \mathrm{psi}$ and is acceptable per ASME Section VIII, even for fatigue applications.

Nozzles "C", "D", "E", "F", and "G" are located at 10-foot intervals axially along the shell for future utility connections, possibly as tracer study injection points or additional DP taps. In the top head, Nozzle " $T$ " was added as a spare 10 -inch flanged connection, with potential uses including auxiliary syngas outlet nozzle, tracer study testing, or a novel level measurement device, such as radar or probe-type devices. Another access port, "N1", was located in the top head to allow access for maintenance and inspection of the top of the tube bundle.

Appendix B, Figure 6 clearly shows the "C"-"G" nozzles (upper row), "K" nozzles (middle row), and " $R$ " nozzles (lower row), as well as all of the nozzles in the bottom head. Figure 9 shows the "J" nozzles, "M" (steam outlet) Inconel nozzles, and most of the nozzles in the top head.

\section{B.1.5 NUCLEAR DENSITY GAUGE AND TRAVERSE ISSUES}

Design of the reactor internals focused on the creation of a 6-inch "window" at the centerline, leaving an obstruction-free path for a nuclear density gauge (NDG). This feature is clearly visible in Appendix B, Figure 4. Because of the long path length across the reactor diameter and heavy wall thickness, the NDG is not strong enough to distinguish variations in slurry density, as accomplished successfully on the LaPorte reactors. Only the presence or absence of slurry will be detected. However, the NDG has provided a reliable means of controlling reactor level at LaPorte, and no other suitable alternative devices were identified which could handle a turbulent slurry environment over a typical startup range of 30 feet. Other devices investigated included radar, sonar, television, conductivity probes, and a nuclear source housed in a pipe inside the reactor (Ohmart).

Since level can vary by a factor of two (e.g. 50\% gas holdup) from a de-gassed slurry to steady state operation, the operator must be able to scan level from approximately 30 to 60 feet. For that reason, a traverse device was designed to move the source and detector in fixed alignment up 
and down the reactor. To minimize obstructions with the traverse, the reactor was designed with almost all nozzles located in one half of the shell. However, the symmetry required by the heat exchanger design to ensure uniform distribution meant that the steam risers would be a potential obstruction. Therefore, in order to scan above the steam headers, the traverse design mandated that the two steam risers turn up immediately outside the vessel and hug the reactor shell until above the traverse pulleys.

Further, it is preferable to have the ability to scan as high into the gas freeboard section as possible for two reasons: the flexibility to increase slurry level, if no entrainment problems occur, thereby increasing the reactor volumetric productivity; and, the ability to scan for a foam layer at the interface. Ultimately, the upper limit on the Kingsport NDG traverse was set by interference between the reactor steel and the traverse pulley system.

Because of the long path length, the nuclear source strength at Kingsport is much stronger than at LaPorte. A special lead-shielded box, with remote shutter access, was engineered to hold the source and to decrease the background radiation below Eastman's standards for personnel exposure.

\section{B.1.6 CALCULATION OF HEAT TRANSFER/STEAM CIRCULATION PERFORMANCE}

The predicted heat transfer characteristics were modeled by modifying a tool used to predict performance of the LaPorte reactors. The slurry-side heat transfer coefficient predictions are based on the proof-of-concept tests at the LaPorte AFDU (1988/89), runs E-5 through E-9. These data were regressed using a Deckwer-type correlation ${ }^{4}$ and documented in the run reports. ${ }^{5,6}$

The principal change to the design practice involved the use of BFW/steam as the internal natural circulation heat transfer fluid, instead of the forced circulation Drakeol-10 loop at LaPorte. Since the steam heat transfer coefficient is dependent on the flow, and since the flow in a natural circulation loop is a function of the pressure drop in the loop, a method of predicting loop pressure drop as a function of flow was added. Furthermore, the ongoing generation of steam along the length of the tubes also affects the pressure drop predictions and the circulation rate. The 50-foot tubes were broken down into discrete, homogeneous sections to predict the change in vapor quality with position and the integrated two-phase pressure drop. The internal heat transfer coefficient was calculated from the Chen correlation for two-phase flow. ${ }^{7}$ Contrary to the LaPorte designs, where the internal fluid controlled the overall heat transfer coefficient, the steam-side coefficient for the Kingsport reactor was nearly an order of magnitude larger than the slurry-side coefficient. 


\section{B.1.7 SPARGER DESIGN}

The fundamental features of the reactor sparger design were first applied to liquid-phase technology in 1987 during design of the simplified LaPorte reactor with the internal heat exchanger. Utilizing this sparger design at LaPorte resulted in dramatic increases in catalyst productivity and gas holdup over the previous distributor.

One key requirement for the Kingsport sparger was the ability to remove it through the reactor access port non-destructively. This prerequisite adds the flexibility to inspect and clean the sparger or to test alternative designs, while still returning to the original design, if desired. As a result, the sparger is flanged in several places. The weight and physical size of each sparger section and the location of the access port were checked to ensure that maintenance personnel could gain access to remove each section. Ultimately, the reactor fabricator installed the sparger through the access port to prove the reversibility of the process. 


\section{B.2 Fabrication}

\section{B.2.1 VENDOR SELECTION AND SHOP REQUIREMENTS}

A fabricator list was developed based on recommendations from Air Products Purchasing and Eastman. Potential bidders were selected based on demonstrated engineering capability and experience with large, clad-plated, heavy-wall vessels. The bidders for the Kingsport reactor were Joseph Oat Corporation, Nooter Corporation, Taylor Forge, and Hahn and Clay.

The successful bidder, Joseph Oat Corporation, was selected after a thorough review of the written proposals and pre-award face-to-face meetings to establish capabilities. Considerations that factored into the final selection included:

- Lowest cost fabricator to meet all specifications.

- Shop loading that allowed for a timely execution of the project.

- Experience managing large, complex projects.

- Convenient location for frequent access by Air Products inspectors.

- Access to rail and barge for transportation.

- Access to a sub-vendor for rolling heavy plate.

- Access to a sub-vendor to perform tight-tolerance perforating/rolling of plates for sparger.

- Access to a sub-vendor for tube bending (internal heat exchanger bundle).

- Access to suppliers of non-standard materials: clad plate, clad forgings, Inconel forgings, duplex 2205 tubing.

- Experience welding heavy-walled carbon steel vessels.

- Experience welding non-standard materials: clad plate, Inconel, and 2205 duplex tubing.

- Experience applying weld overlay to surfaces that could not be clad by explosion bonding.

- Access to a sub-vendor for orbital welding the internal heat exchanger bundle.

- Ability to perform post-weld heat treatment of large vessels.

- Work practices in place that minimized the potential for iron contamination of the surfaces exposed to slurry. Possible sources of contamination included weld spatter, airborne particulates, rollers/wire brushes/tools, and filings adhering to clothes and shoes.

- Ability to complete required testing and inspection:

- $100 \%$ radiography of all butt-welds on internal heat exchanger; these welds are all inaccessible after final assembly of the reactor.

- Liquid penetrant test of all welds.

- Copper Sulfate or Feroxyl test of all final welds on clad surfaces to ensure no iron contamination of the $304 \mathrm{~L}$ internal surface.

- Hydrotest of internal bundle and assembled reactor.

- Access to a video borescope to verify full penetration of welds on the internal heat exchanger where $\mathrm{x}$-ray was not feasible.

- Cranes and lifting equipment for moving the assembled $270,000 \mathrm{lb}$ vessel as well as subassemblies (heads, shell sections, internal heat exchanger bundle, manway plug, etc.) 
- Engineering capabilities to include:

- Ability to perform ASME Section VIII Division 1 Code calculations.

- Ability to perform seismic and wind analyses to design an appropriate tapered skirt and baseplate.

- Access to a computer-based stress analysis tool to confirm the ability of the internal heat exchanger to withstand the thermal stresses imposed during operation and upset.

- Ability to produce drawings to show dimensions and fabrication details and to check clearances.

- Ability to design support details: lift lugs, tail lugs, trunnions, and internal supports for the heat exchanger bundle.

- Ability to develop shipping and rigging procedures and design temporary shipping saddles.

- Capacity to pickle and passivate the vessel in the shop, although ultimately this capability was not used because the vessel was passivated after installation at the site.

- Experience with sandblasting and painting.

The project schedule needed to incorporate a significant period of time for non-standard material procurement. The clad plate for the heads and shell sections, and the 2205 duplex tubing had a lead time of 20 to 22 weeks. Other long-lead items included the Inconel nozzle forgings and the pre-clad nozzle forgings.

\section{B.2.2 SCHEDULE - PROPOSED vs. ACTUAL}

Table 1 lists the major schedule milestones for the reactor design, fabrication, and installation. The reactor ultimately shipped from Joseph Oat's shop on June 14, 1996, eight months after the original 11-month schedule. The other three bidders also quoted 8- to 11-month schedules for design and fabrication.

The scheduled ship date of the reactor slipped in modest increments throughout the order, including a 7-week delay in February 1995, another 12-week delay by October 1995, another 4week delay by April 1996, and another 11 weeks by the time the unit shipped. However, the detailed mechanical design of the reactor did not contribute significantly to the overall delays experienced. The main problems were caused by fabrication errors, quality control issues, shop equipment problems, and sub-vendor delays. 
Table 1

Kingsport LPMEOH ${ }^{\mathrm{TM}}$ Reactor Schedule Milestone Dates

\section{Activity}

\begin{tabular}{l}
$\begin{array}{l}\text { Purchase Order } \\
\text { Promise Date }\end{array}$ \\
\hline
\end{tabular}

1. Issue Process Specification Rev. 0

2. Issue Mechanical Specification for Bidding, Rev. 0

3. Receive Bids

4. Award Purchase Order

5. Kick-off Meeting

6. Air Products Release J. Oat to Order Materials

7. First Series Vendor Prints Issued

8. J. Oat Complete Detail Drawings

9. Receive Shell Materials

10. Receipt of Internal Exchanger Pipe Materials

11. Problem Rolling Shell Plates at Coastal

12. Receive Reactor Heads

13. Start Fabrication of Reactor

14. Plate Rolling Put On-Hold

15. Agreed to Annealing Process

16. Sensitized Plates Heat Treated

17. Complete Rolling Shells

18. Post Weld Heat Treat Shell

19. Install Internal Heat Exchanger in Shell

20. Hydrotest Reactor

21. Ship Reactor

22. Arrive On Site

23. Install Reactor at Site

24. Pickle and Passivate Reactor

25. Complete Piping to Reactor

26. Plant Start-up

\section{Completion}

Date

$06 / 24 / 94$

$08 / 26 / 94$

$10 / 03 / 94$

$11 / 04 / 94$

$11 / 17 / 94$

$12 / 21 / 94$

$12 / 28 / 94$

$04 / 26 / 95$

$04 / 28 / 95$

$05 / 05 / 95$

$06 / 05 / 95$

$06 / 06 / 95$

$07 / 20 / 95$

$07 / 21 / 95$

$09 / 15 / 95$

$10 / 02 / 95$

$10 / 20 / 95$

$03 / 08 / 96$

04/09/96

$05 / 24 / 96$

$10 / 09 / 95 \quad 06 / 14 / 96$

$06 / 29 / 96$

$07 / 02 / 96$

08/24/96

$02 / 10 / 97$

03/01/97 


\section{B.2.3 PROBLEMS AND SOLUTIONS}

Numerous problems and delays occurred during fabrication of the Kingsport LPMEOH ${ }^{\mathrm{TM}}$ reactor. The reactor design was a complex, first-of-a-kind effort that presented many challenges for the vendor, including development of new methods for fabricating some of the components that went into the finished unit. Table 2 lists the major difficulties encountered and an estimate of their impact on the reactor shipping date.

Table 2

Kingsport LPMEOH ${ }^{\mathrm{TM}}$ Reactor Fabrication Problems

\section{Problem}

1. Delay in Air Products release for ordering materials

2. Sensitization of shell plates

3. Orbital welding of internal bundle tubes (establishing weld procedure and then passing X-ray exam)

4. Fabrication of sparger

5. Weld repairs to shell girth seam

6. Nozzle interference with power rollers

7. Removal of carbon steel weld spatter from internal stainless steel shell

8. Lack of or breakdown of power rollers for completed shell

9. Insertion of internal heat exchanger into reactor

10. Underestimate of man-hours and time to complete some operations

* Beyond original plan (purchase order dates for reactor).

** Not critical path item.
Estimated

Delay (weeks)*

2

22

$4+* *$

$13^{* *}$

4

1

1

2

1

Not quantified 
The major 22-week delay occurred when a subcontractor erroneously heat-treated the clad plate in an attempt to soften the metal properties of the plate to facilitate rolling in a relatively small diameter. This procedure "sensitized" the stainless cladding on three of the seven metal plates required to fabricate the reactor shell. The three plates affected had the highest measured carbon content in the cladding. "Sensitization" implies a loss of corrosion resistance at the grain boundaries caused by the formation of chromium carbides. To treat this problem, the three plates were "solution annealed" in a controlled heat treatment which forces the carbon back into "solution" in the metal and away from the grain boundaries. After treatment, the plates were tested by ASTM methods and found to be acceptable. In future LPMEOH ${ }^{\mathrm{TM}}$ mechanical specifications, sensitized stainless steel should be clearly defined as unacceptable, and the contractor should be instructed how to avoid sensitization of stainless cladding during fabrication.

Even simple considerations caused schedule delays, however minor. For example, Appendix B, Figure 3 shows how the 4-foot spacing of the " $\mathrm{J}$ " nozzles caused an interference with the rollers used to turn the reactor through $360^{\circ}$ under automatic welding machines (i.e. the rollers were more than 4 feet wide). This complication prolonged the welding of the head-to-shell seam by one week (Item \#6 on Table 2). Early in the design phase of future reactors, the fabricator should review the proposed nozzle arrangement for compatibility with their shop equipment.

Because of the sensitivity of this first-of-a-kind design, Air Products dedicated an inspector to the reactor fabrication process. The quality control checks were rather extensive and, in fact, uncovered numerous errors that required rework. For example, the inspector found several internal welds made with carbon steel welding rods, which the vendor subsequently cut out and rewelded (Item \#5 on Table 2). Elsewhere, the inspector found some iron contamination from weld spatter, and a large section of stainless steel weld overlay missed at a nozzle connection. Cleaning or repairing, passivating, and retesting these areas caused further delays (Item \#7 on Table 2).

In addition, the individual fabrication steps were more complex than anticipated and required significantly more hours than originally estimated. Ultimately, however, the unit did pass the hydrotest and all other quality control tests, and it has performed satisfactorily in operation thusfar. 


\section{B.3 Shipment to Site}

The Kingsport LPMEOH ${ }^{\mathrm{TM}}$ reactor overall shipping dimensions were: 76 feet long and $111 / 2$ feet wide with a shipping weight of 270,000 pounds. The shipping height, after placement on a transporter, eliminated any serious consideration of shipping the reactor by truck. Instead, the project team chose to ship the reactor by rail from Joseph Oat's shop.

Although the reactor internal diameter is $7 \frac{1}{2}$ feet, the vessel skirt and base ring create the maximum shipping dimension of 11 feet, 5 inches. The length of the reactor required an idler car on either end of the transport car.

Air Products' Logistics Department worked with Joseph Oat and Conrail, the local rail carrier servicing Joseph Oat's shop, to coordinate the planning, ordering, loading, shipment, and offloading of the reactor. Joseph Oat worked with Air Products and Conrail to design the shipping saddles and hold downs. Joseph Oat's bridge cranes were used to load the unit at $90^{\circ}$ to the car. A special swivel saddle was designed for holding one end of the reactor on the railcar while bringing the other end into position. Appendix B, Figure 6 shows the reactor mounted on the railcar.

An outside expediter, hired by Air Products to follow the reactor to Kingsport, subsequently prevented Conrail from mis-routing the shipment in Ohio. After arriving in Kingsport, the reactor was jacked off the railcar and loaded onto special transporters by the Oswalt Company. The transporters moved the reactor to the job-site over a weekend, because the state would not allow movement of such a large load during the week. The total cost for the rail shipment, offloading in Kingsport, and delivery to the job-site was \$71,530 (not including Air Products internal cost).

The original estimated transit time by rail was 14 to 41 days. Ultimately, 32 days elapsed from the time the reactor was ready to ship until it was ready for lifting at the job-site in Kingsport. The major time components for the shipment were:

\section{Elapsed Time}

$\begin{array}{ll}\text { Rail Car Arrival for Loading } & 10 \text { days } \\ \text { Loading Reactor on Car } & 4 \text { days } \\ \text { Inspection by Conrail } & 1 \text { day } \\ \text { Shipment by Conrail from Camden, NJ to Coatesville, PA to Columbus, OH } & 6 \text { days } \\ \text { CSX Inspection } & 1 \text { day } \\ \text { Shipment to Kingsport, TN } & 3 \text { days } \\ \text { Delivery to Off-loading Spur } & 2 \text { days } \\ \text { Transloading from Rail Car to Transporters } & 1 \text { day } \\ \text { Delay to Ship on Weekend Only (State Requirement) } & 3 \text { days } \\ \text { Shipment to Site } & 1 \text { day }\end{array}$




\section{B.4 Installation and Passivation}

The LPMEOH ${ }^{\mathrm{TM}}$ reactor is designed to be supported on a short skirt attached to the base of the vessel. It sits on a structural steel "tabletop" approximately 10 feet above grade (shown in Appendix B, Figure 7). The structure is open at the base to allow access to the valving and piping connected to the bottom head of the reactor.

The reactor was set in place using a Demag TC1200 300-ton lattice-boom truck crane with a heavy-lift attachment for the main lift, and a Krupp KMK 6200 300-ton hydraulic truck crane as the tailing crane. Appendix B, Figure 8 shows the reactor during the lift. The base ring was bolted to the structural steel supports and shimmed in a few locations to set the unit plumb. The reactor was erected to within $1 / 64$ inch per foot with a maximum of $\pm 1 / 2$ inch utilizing transits set $90^{\circ}$ apart.

After the reactor was set in place, the structural steel for supporting and accessing the reactor instrumentation, piping, and ancillary equipment (i.e., steam drum, feed/product economizer, cyclone, etc.) was set in place. Actually, the structure was designed so that the reactor could be set after completion of the steel erection, but this alternative would have required a much larger (and more expensive) crane.

As mentioned previously, contamination of the metal surfaces in the reactor can cause formation of catalyst poisons during operation. At LaPorte, equipment and piping has typically undergone a two-step cleaning process of pickling and passivation to eliminate the possibility of surface contamination. During the design of the Kingsport reactor, materials experts advised that the first pickling step was actually unnecessary and passivation alone would be adequate. As a result, the cleaning specification for the reactor was relaxed to include only passivation.

However, the method and sequence of cleaning steps during fabrication became another issue of concern.

The preferred cleaning steps and sequence were:

1. Sandblast the reactor shell with an iron-free sand after completion of all welding. This step was actually skipped for the Kingsport reactor, because Joseph Oat was unable to move such a large vessel to an area suitable for sandblasting and then move it back again for final fabrication. The vessel received a mild sandblast prior to fit up of the shell courses and nozzles, but the internal surfaces were exposed to dirt, grit, and weld spatter during the balance of fabrication. After final assembly and prior to insertion of the internal coils, areas of possible surface iron contamination (especially, all internal weld closures on clad surfaces) were wire brushed, locally passivated with a nitric acid solution, and then tested with a copper sulfate solution for traces of iron.

2. Degrease the reactor and rinse with potable water.

3. Passivate the vessel with a $20 \%$ nitric acid solution at ambient temperatures.

4. Rinse the vessel with potable water until a neutral $\mathrm{pH}$ is achieved. 
Joseph Oat proposed passivating the Kingsport reactor earlier in the fabrication process, prior to post-weld heat treatment and installation of the internal heat exchanger bundle. The size of the reactor vessel drove this recommendation because they would be unable to locate the vessel over their drainage system unless the shell was in two parts. They were also unable to stand the vessel upright to ensure proper drainage of the passivating solution. As designed, if the Kingsport reactor was passivated in the horizontal position, the spray wands could not reach into the heat exchanger bundle to ensure adequate cleaning of all surfaces. As a result, the reactor was passivated after installation at the site, so that gravity could assist in the washing.

After the reactor was installed, and prior to connecting any piping, a portable circulation system was set up at the Kingsport construction site. The reactor was cleaned and passivated by circulating first a mild detergent, then a $20 \%$ nitric acid solution, and then a final rinse through the vessel. The various solutions were sprayed in at the top of the reactor through a swirling wand assembly that was able to ensure thorough coverage of the internals. 


\section{B.5 Future Reactor Scale-up Considerations}

Air Products has begun to contemplate the practical constraints on scale-up for potential future opportunities, where the reactor dimensions may grow by yet another factor of two. Two of the obvious considerations affecting maximum possible reactor size are shipping constraints and fabrication shop capabilities.

\section{B.5.1 SHIPPING CONSTRAINTS}

The Kingsport LPMEOH ${ }^{\mathrm{TM}}$ reactor was large enough to require shipment by rail. Some of the limitations for rail shipments are listed below.

\section{Car Type}

Heavy Duty Car

TTX New Cars

Bolster Load Two Cars

ABB Schnable Car

\section{Weight (lbs)}

$500 \mathrm{~K}$

$738 \mathrm{~K}$

$900 \mathrm{~K}$

$1,000 \mathrm{~K}$

\section{Notes}

No longer than 44 feet.

Only four cars exist.

Load on two cars.

One of a kind car; maximum length about 72 feet; cost around $\$ 92 \mathrm{~K}$ per move; allows side shifting enroute to avoid obstructions.

Shipment of any large vessel by rail must take into account weight, length, width, height, and route. Some heavy-duty cars can only carry short equipment (i.e., no longer than 44 feet). Some routes have bridges that cannot carry heavy weights. Some of the cars are scarce, and some are very expensive. A generic maximum on a single rail car is 100 feet long by $12 \frac{1}{2}$ feet wide by 14 feet high including saddle and cribbing.

Larger and heavier reactors can be shipped by barge or ocean transport. Whether the reactor is shipped by rail or barge, the fabrication shop and job site must be accessible to these modes of transport. 


\section{B.5.2 FABRICATION SHOP CAPABILITIES}

There are a limited number of fabrication shops worldwide that can handle large, customfabricated, heavy-walled vessels. Any future scale-up of the reactor may further limit the list of potential fabricators to those who can roll heavier plate and have the crane capability to lift heavier vessels. For example, based on the Joseph Oat crane limitation of $410,000 \mathrm{lbs}$, the maximum dimensions of a scaled-up reactor (1000 psig @ $600^{\circ} \mathrm{F}$ MAWP) would be:

\section{Wall Thickness (inches)}

5

4

$31 / 2$

\section{Outside Diameter (feet)}

15

12

10

\section{Maximum Length (feet)}

50

91

135

Anything larger would require a shop with superior crane capabilities. In addition, because of the aforementioned shipping constraints, barge access may be required.

Air Products has worked with a few such fabrication shops in the past and has established procedures for ensuring that a quality product is shipped to the customer. 


\section{Conclusion}

The LPMEOH ${ }^{\mathrm{TM}}$ process uses a slurry bubble column reactor to convert syngas to methanol. Because of its superior heat management, the process can utilize directly the CO-rich syngas characteristic of the gasification of coal, petroleum coke, residual oil, wastes, or other hydrocarbon feedstocks.

The LPMEOH ${ }^{\mathrm{M}}$ Demonstration Project at Kingsport, Tennessee, is a $\$ 213.7$ million cooperative agreement between the U.S. DOE and Air Products Liquid Phase Conversion Company, L.P., a partnership between Air Products and Chemicals, Inc. and Eastman Chemical Company, to produce methanol from coal-derived syngas. Construction of the LPMEOH ${ }^{\mathrm{TM}}$ Process Demonstration Plant at Eastman's chemicals-from-coal complex in Kingsport was completed in January 1997. Following commissioning and shakedown activities, the first production of methanol from the facility occurred on April 2, 1997. Nameplate capacity of 260 TPD was achieved on April 6, 1997, and production rates have exceeded 300 TPD of methanol at times.

This report described the design, fabrication, and installation of the Kingsport LPMEOH ${ }^{\mathrm{TM}}$ reactor, which was the first commercial-scale $\mathrm{LPMEOH}^{\mathrm{TM}}$ reactor ever built. The vessel is 7.5 feet in diameter and 70 feet tall with design conditions of $1000 \mathrm{psig}$ at $600^{\circ} \mathrm{F}$. These dimensions represent a significant scale-up from prior experience at the AFDU, where 18-inch and 22-inch diameter reactors have been tested successfully over thousands of hours. The biggest obstacles discovered during the scale-up, however, were encountered during fabrication of the vessel. The lessons learned during this process must be considered in tailoring the design for future sites, where the reactor dimensions may grow by yet another factor of two.

Although simpler in many respects than its conventional counterparts, the Kingsport LPMEOH ${ }^{\mathrm{TM}}$ reactor design was a complex, first-of-a-kind effort that presented many challenges for the vendor, including development of new methods for fabricating some of the components that went into the finished unit. The project schedule needed to incorporate a lead time of 20 to 22 weeks for non-standard material procurement, such as stainless steel-clad plate, 2205 duplex alloy tubing, and Inconel nozzle forgings. Even including this consideration, the reactor ultimately shipped from the vendor on June 14, 1996, eight months after the original 11-month schedule. The main problems were caused by fabrication errors, quality control issues, shop equipment problems, and sub-vendor delays. 


\section{References}

1. Dechema Corrosion Handbook: Corrosive Agents and their Interaction with Materials, Vol. 9 (1991), 35-38.

2. J. Bryanestad, Iron and Nickel Carbonyl Formation in Steel Pipes and Its Prevention Literature Survey ORNL/TM - 5499 Sept. 1976. Contract No. 7405 eng 26 Oak Ridge National Laboratory.

3. Bhatt, B. L., "Liquid Phase Fluid Dynamic (Methanol) Run in the LaPorte Alternative Fuels Development Unit," Topical Report prepared for the U.S. Department of Energy under Contract No. DE-FC22-95PC93052, May 1997, 14.

4. Deckwer, W. D., "Hydrodynamic Properties of the Fischer-Tropsch Slurry Process," Ind. \& Engrg. Chem. Process Design and Development, 19 (1980), 699-708.

5. Air Products and Chemicals, Inc., "Task 2.0: Run E-5, Gas Hold-up and Equipment Evaluation Studies," Topical Report prepared for the U.S. Department of Energy under Contract No. DE-AC22-87PC90005, January 1991, 51-56.

6. Air Products and Chemicals, Inc., "Task 2.2: Alternate Catalyst Run E-6 and Catalyst Activity Maintenance Run E-7," Topical Report prepared for the U.S. Department of Energy under Contract No. DE-AC22-87PC90005, February 1991, 28-35, 71-75.

7. Chen, J. C., "Correlation for Boiling Heat Transfer to Saturated Fluids in Convective Flow," Ind. \& Engrg. Chem. Process Design and Development, 5 (1966), 322-329. 


\section{APPENDICES}

APPENDIX A - PROCESS FLOW DIAGRAM AND REACTOR GENERAL ARRANGEMENT DRAWING 


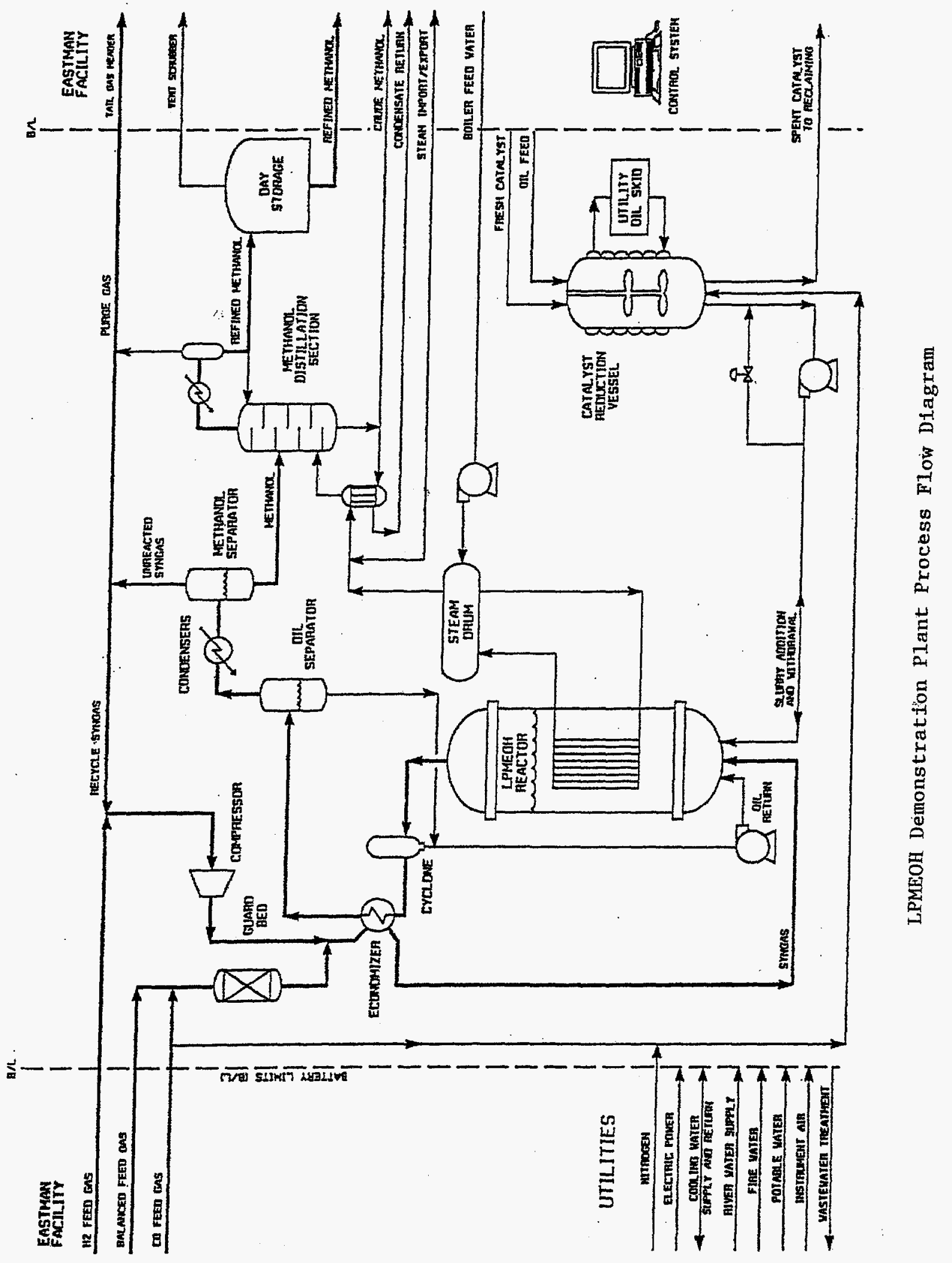




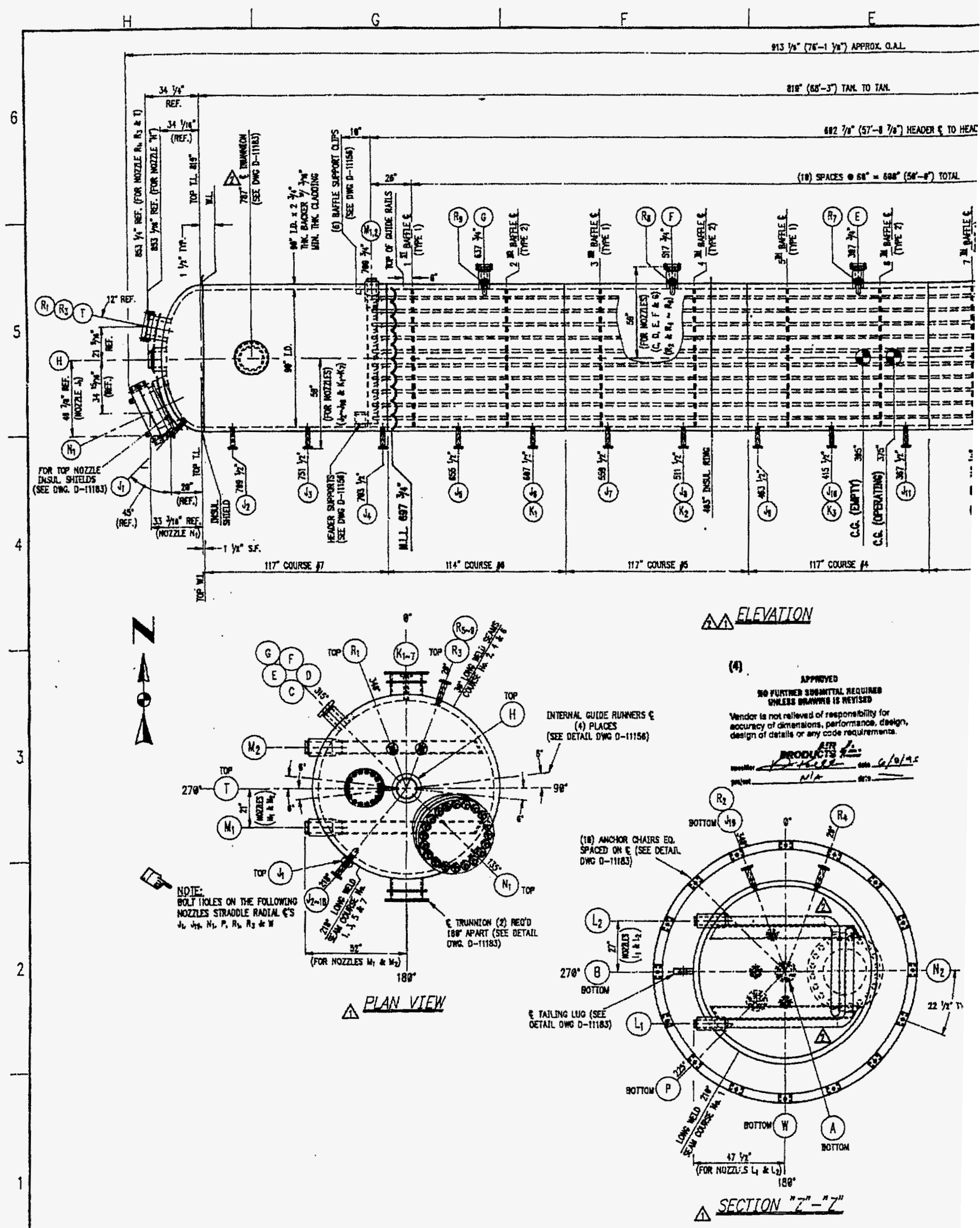


A

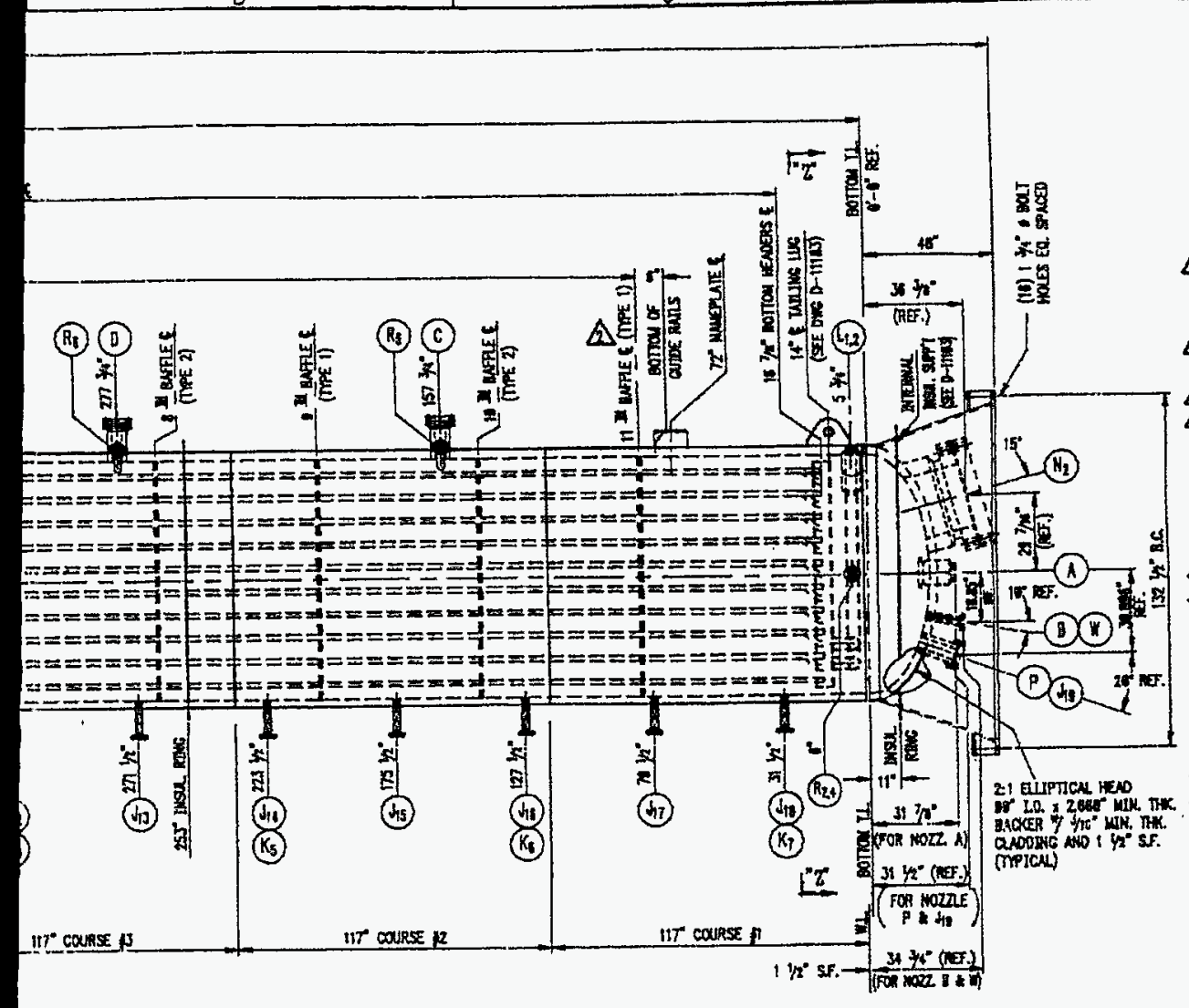

\begin{tabular}{|c|c|c|}
\hline DESIGH DATA & SHEII SIDE & TUBE STOE \\
\hline APPLICAGLE COOES & \multicolumn{2}{|c|}{ 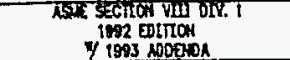 } \\
\hline DESTOU PAESSTIFe & FV/ $1 \mathrm{mPSSC}$ & FV / SA PSTO \\
\hline cestou tupesunua & 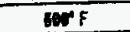 & $\omega F F$ \\
\hline 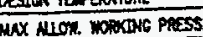 & FV/ / P PSTE & N/AH PSL \\
\hline
\end{tabular}

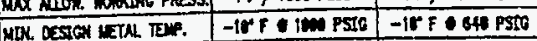

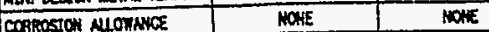

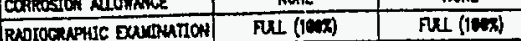

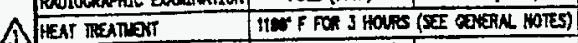

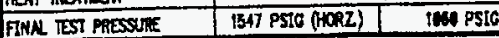
FIHN TEST PRESSUL ILE WATERIAL

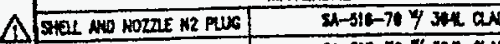

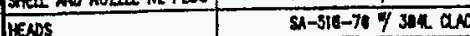

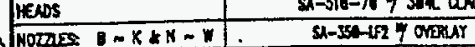

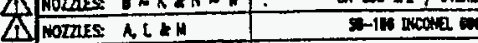

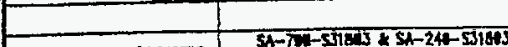

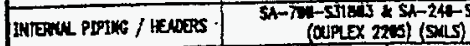
\begin{tabular}{|l|c|c|}
\hline BNFES & - & 304 \\
\hline
\end{tabular}

Iniming A) wallow whe

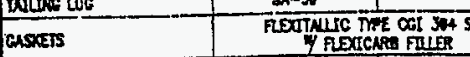

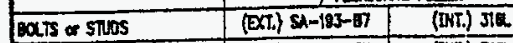
\begin{tabular}{|l|l|l}
\hline WuTs & (DT.) SA-104-2H & (INT.) 310L \\
\hline
\end{tabular}

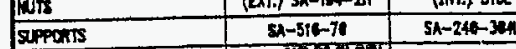

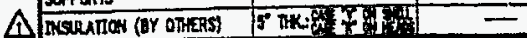

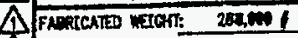

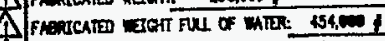

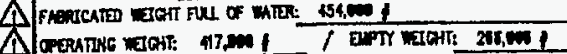

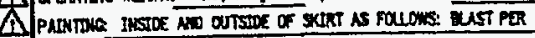
SSPC ST-5 (1-3 WLS PROFIIS WD NPPY (U) COAT CABBOZOHC UTHS 4

(2-3 wers D.F.T.)

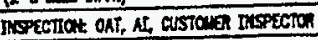

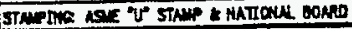

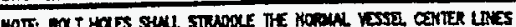
WeSS OHERT: MOTE

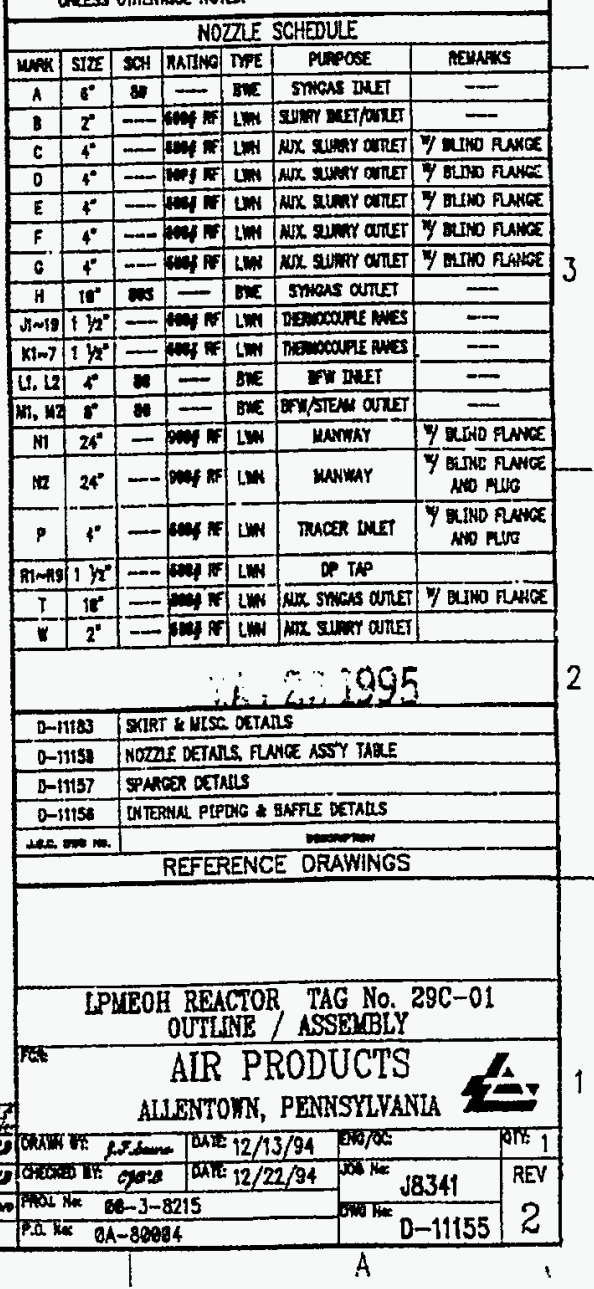

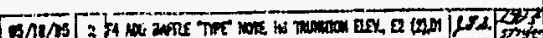

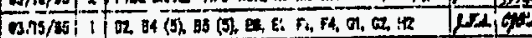

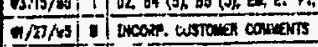
- $x: \Delta]$ REVISIONS $\frac{\operatorname{los} 2}{\operatorname{los} 20}$ 
APPENDIX B - PHOTOGRAPHS OF REACTOR FABRICATION, SHIPMENT, AND

INSTALLATION 


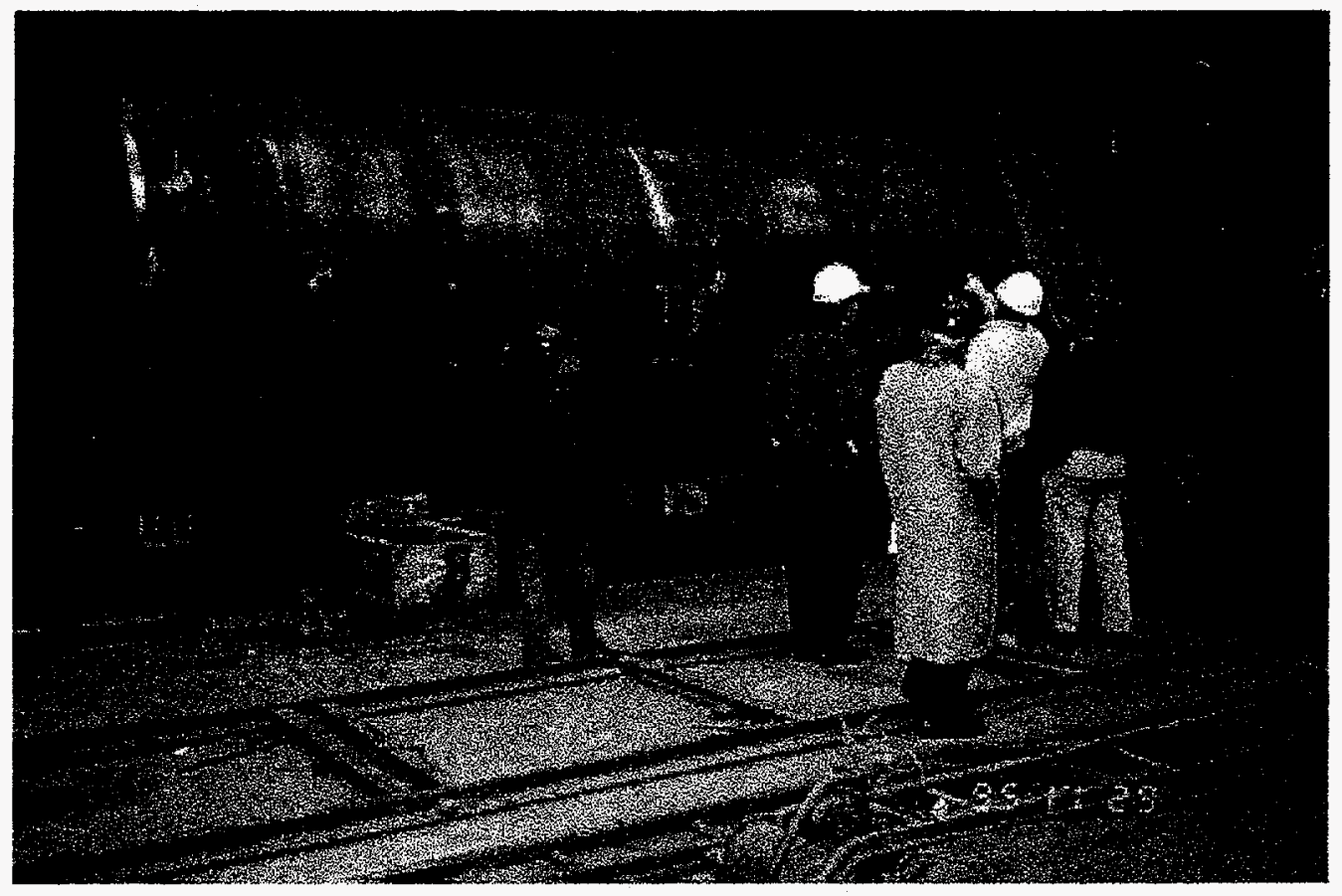

Figure 1 - Fabrication of Reactor Shell

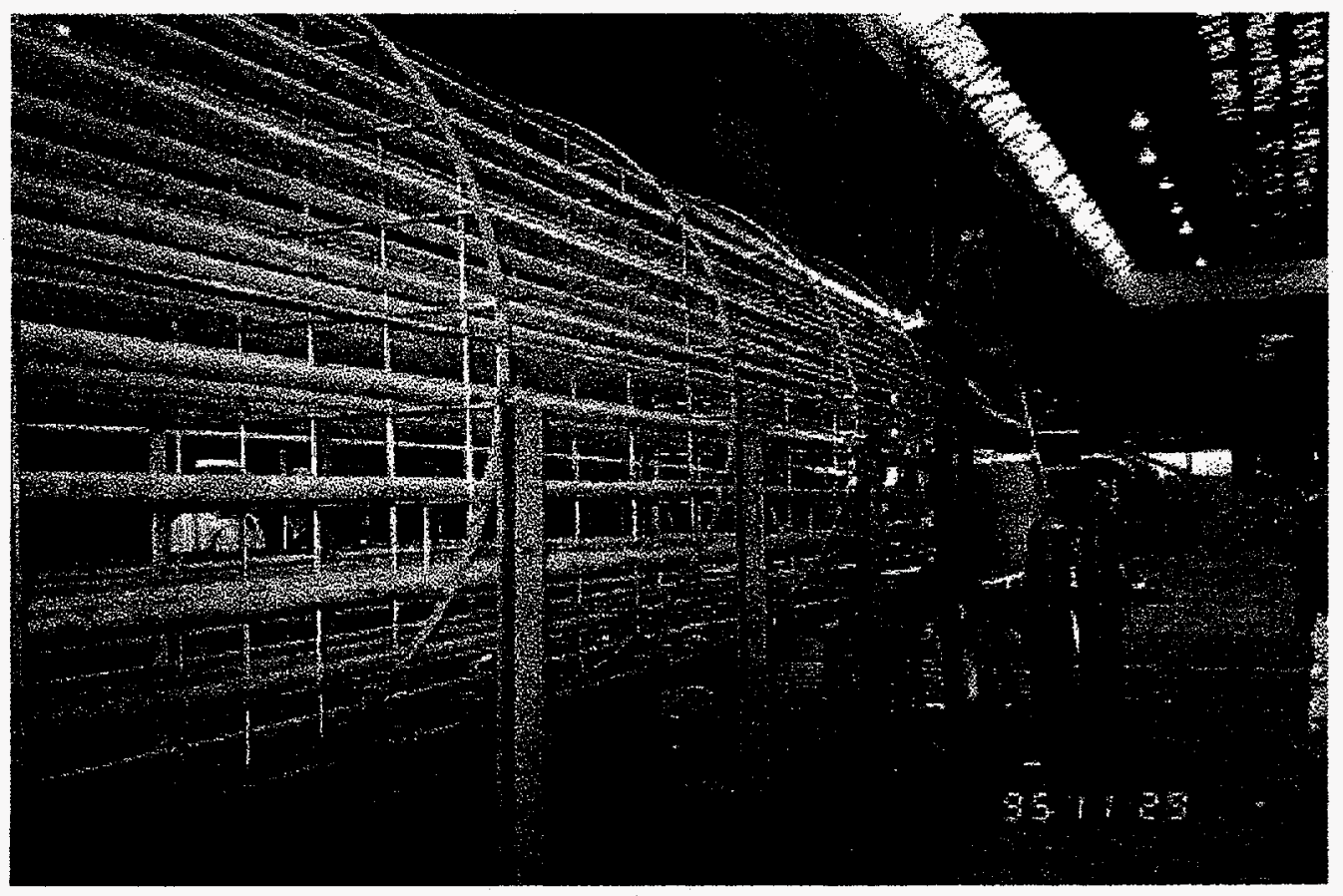

Figure 2 - Fabrication of Internal Heat Exchanger 


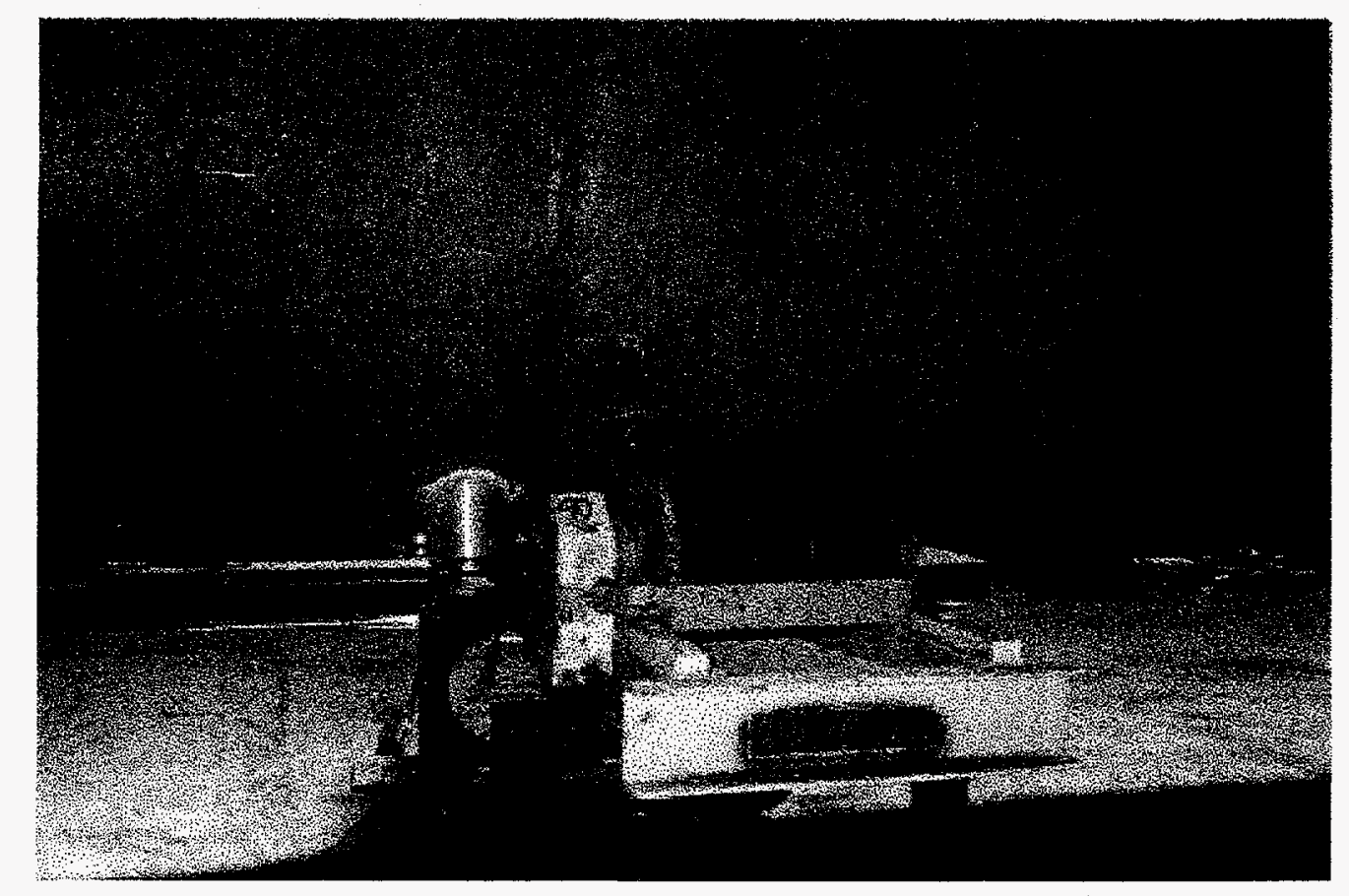

Figure 3 - Nozzle Interference with Power Rollers

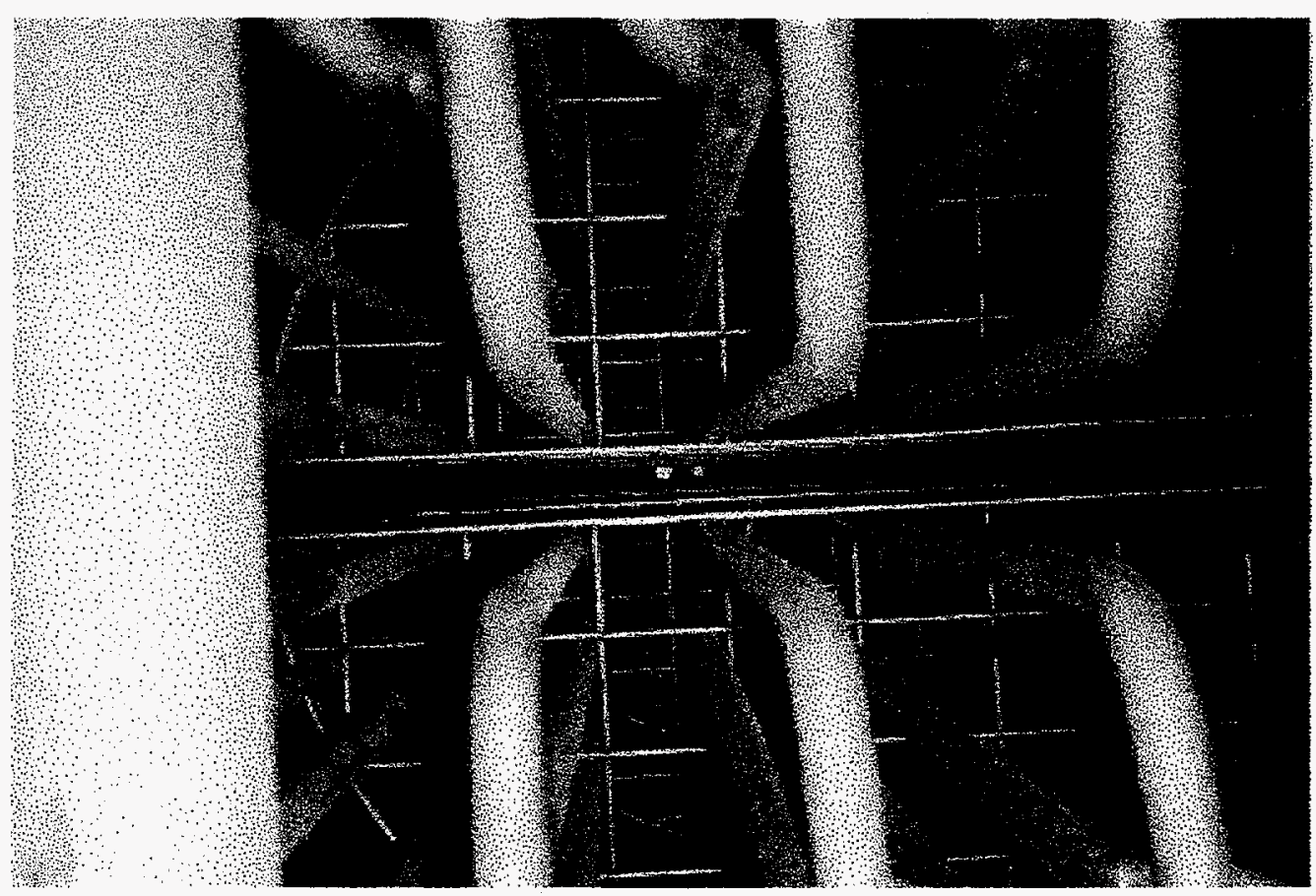

Figure 4 - Nuclear Density Gauge "Window" through Internal Heat Exchanger 


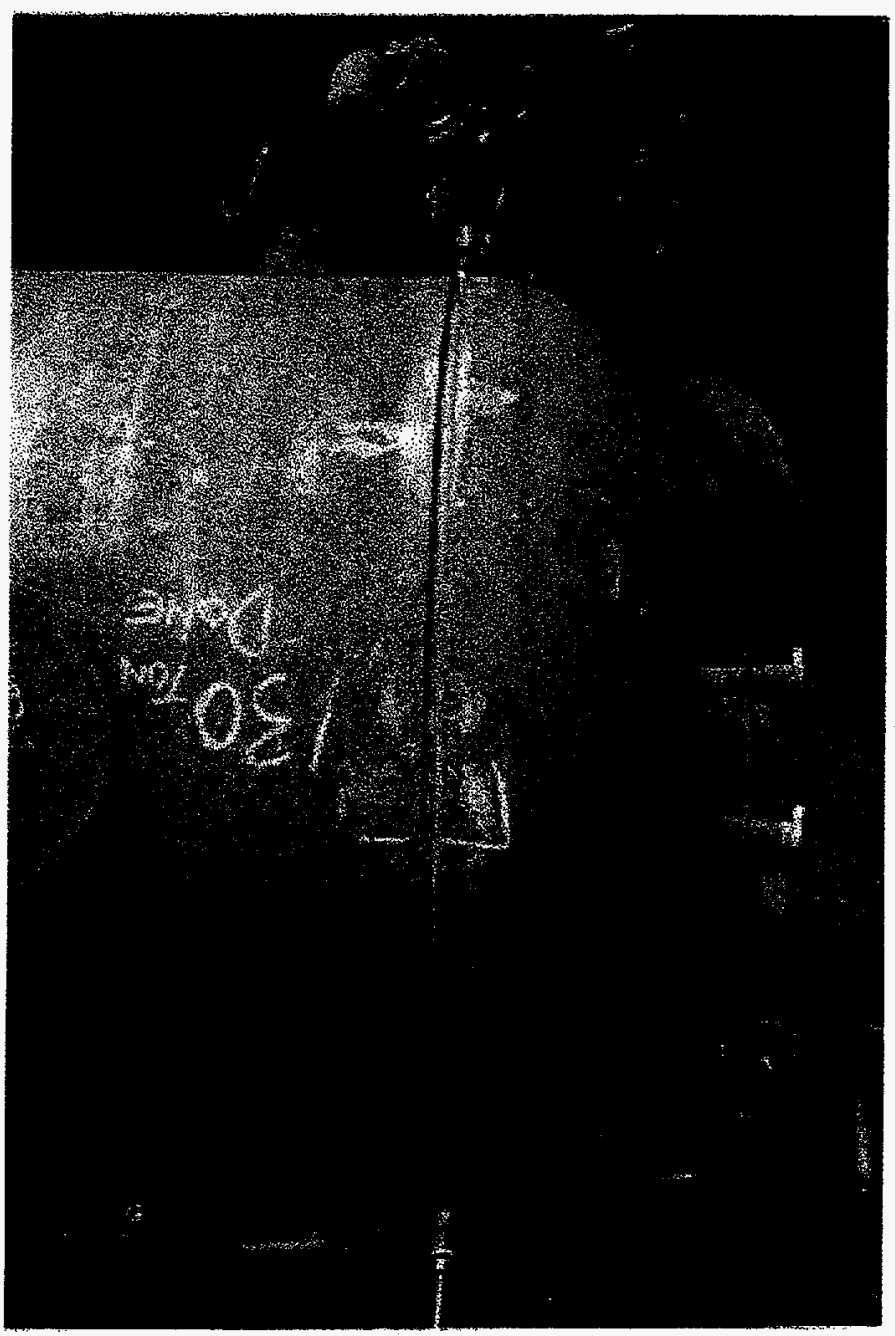

Figure 5 - Welding of Head-to-Shell Seam 


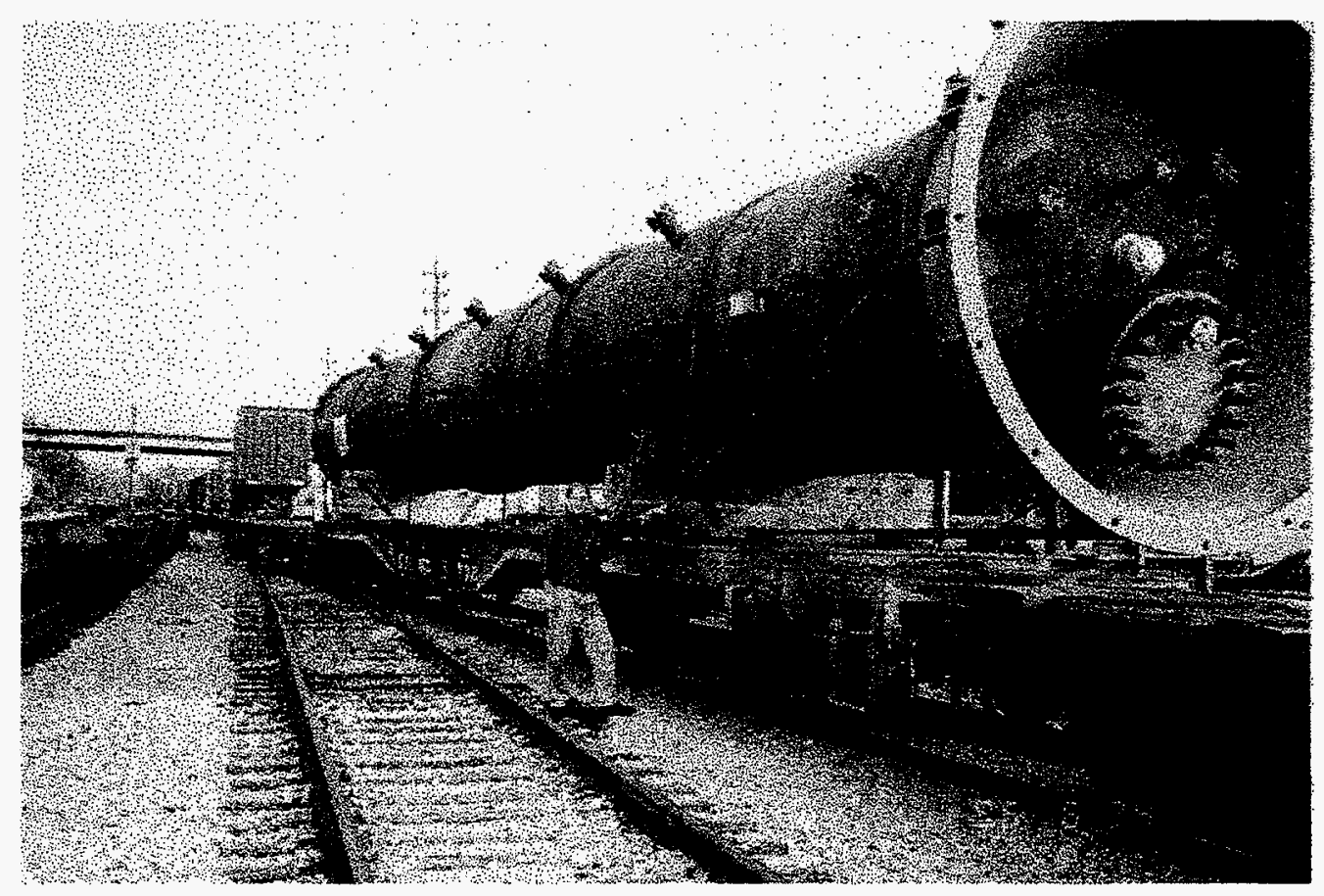

Figure 6 - Reactor Loaded on Rail Car

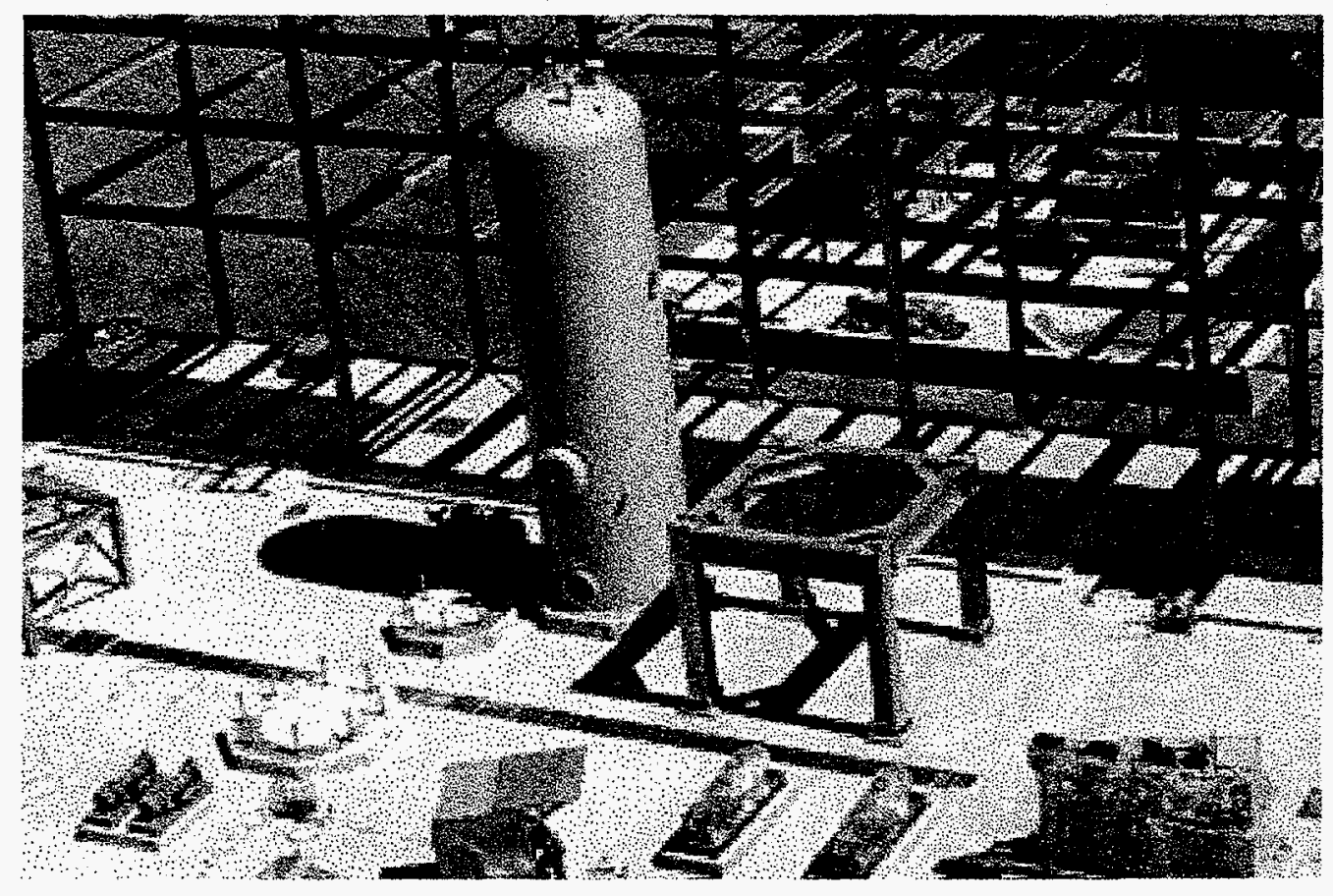

Figure 7 - "Tabletop" for Reactor Mounting 


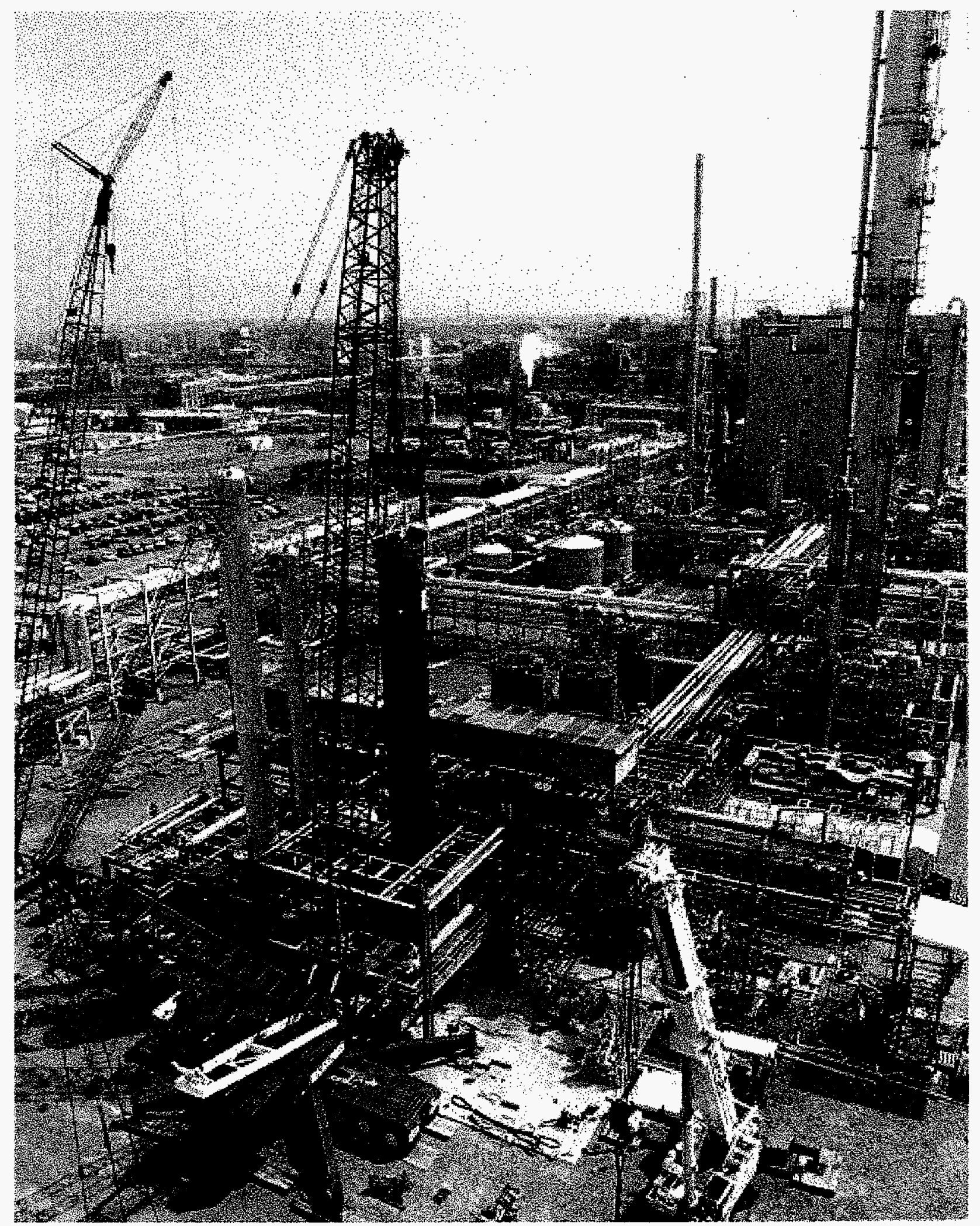

Figure 8 - Reactor Installation 


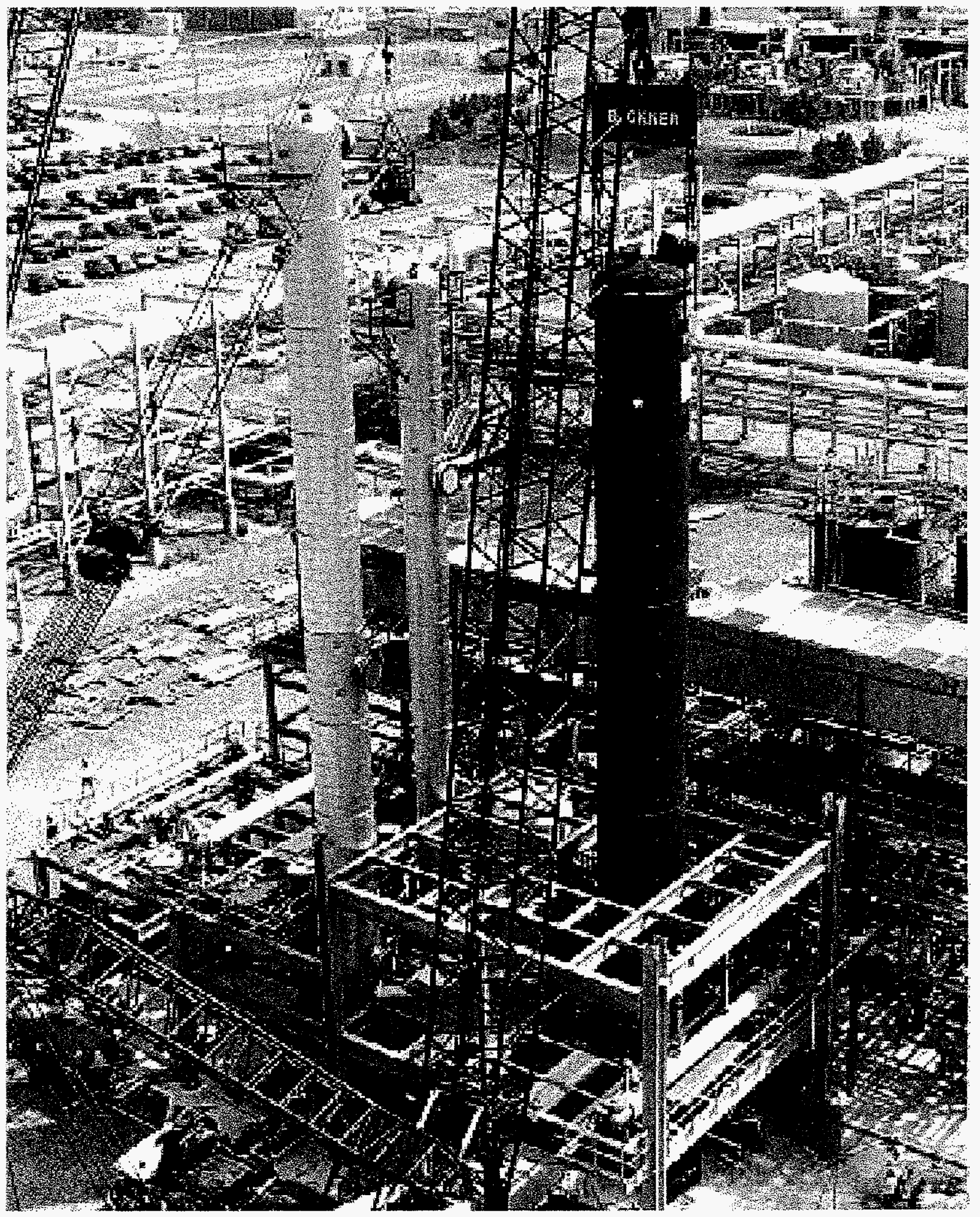

Figure 9 - Reactor Installation 